\title{
Article \\ Osmotic Adaptation and Compatible Solute Biosynthesis of Phototrophic Bacteria as Revealed from Genome Analyses
}

\author{
Johannes F. Imhoff ${ }^{1, *(\mathbb{D})}$, Tanja Rahn ${ }^{1}$, Sven Künzel ${ }^{2}$, Alexander Keller ${ }^{3} \mathbb{D}$ and Sven C. Neulinger ${ }^{4}(\mathbb{D})$ \\ 1 GEOMAR Helmholtz Centre for Ocean Research, 24105 Kiel, Germany; trahn@geomar.de \\ 2 Max Planck Institute for Evolutionary Biology, 24306 Plön, Germany; kuenzel@evolbio.mpg.de \\ 3 Center for Computational and Theoretical Biology, University Würzburg, 97074 Würzburg, Germany; \\ a.keller@biozentrum.uni-wuerzburg.de \\ 4 omics2view.consulting GbR, 24118 Kiel, Germany; s.neulinger@omics2view.consulting \\ * Correspondence: jimhoff@geomar.de
}

Citation: Imhoff, J.F.; Rahn, T.;

Künzel, S.; Keller, A.; Neulinger, S.C. Osmotic Adaptation and Compatible Solute Biosynthesis of Phototrophic Bacteria as Revealed from Genome Analyses. Microorganisms 2021, 9, 46. https://doi.org/10.3390/

microorganisms 9010046

Received: 3 December 2020 Accepted: 23 December 2020 Published: 26 December 2020

Publisher's Note: MDPI stays neutral with regard to jurisdictional clai$\mathrm{ms}$ in published maps and institutional affiliations.

Copyright: $(\odot 2020$ by the authors. Licensee MDPI, Basel, Switzerland. This article is an open access article distributed under the terms and conditions of the Creative Commons Attribution (CC BY) license (https:// creativecommons.org/licenses/by/ $4.0 /)$.

\begin{abstract}
Osmotic adaptation and accumulation of compatible solutes is a key process for life at high osmotic pressure and elevated salt concentrations. Most important solutes that can protect cell structures and metabolic processes at high salt concentrations are glycine betaine and ectoine. The genome analysis of more than 130 phototrophic bacteria shows that biosynthesis of glycine betaine is common among marine and halophilic phototrophic Proteobacteria and their chemotrophic relatives, as well as in representatives of Pirellulaceae and Actinobacteria, but are also found in halophilic Cyanobacteria and Chloroherpeton thalassium. This ability correlates well with the successful toleration of extreme salt concentrations. Freshwater bacteria in general lack the possibilities to synthesize and often also to take up these compounds. The biosynthesis of ectoine is found in the phylogenetic lines of phototrophic Alpha- and Gammaproteobacteria, most prominent in the Halorhodospira species and a number of Rhodobacteraceae. It is also common among Streptomycetes and Bacilli. The phylogeny of glycine-sarcosine methyltransferase (GMT) and diaminobutyrate-pyruvate aminotransferase (EctB) sequences correlate well with otherwise established phylogenetic groups. Most significantly, GMT sequences of cyanobacteria form two major phylogenetic branches and the branch of Halorhodospira species is distinct from all other Ectothiorhodospiraceae. A variety of transport systems for osmolytes are present in the studied bacteria.
\end{abstract}

Keywords: genomes of photosynthetic bacteria; glycine betaine biosynthesis; ectoine biosynthesis; osmotic adaptation; phylogeny of osmolyte biosynthesis

\section{Introduction}

Phototrophic bacteria are widely distributed at suitable habitats in the marine and hypersaline environment. They are exposed to sometimes dramatically changing salt concentrations and some are found in saturated brines of salt and soda lakes, where they regularly develop massive blooms, often forming patches and pinkish-red layers, even within deposits of crystalized salts [1,2]. One of the prerequisites to cope with high salt and solute concentrations is the ability to keep an osmotic balance, i.e., a positive turgor pressure inside the cells through the accumulation of solutes in the cytoplasm that are compatible with the metabolic processes, even at high concentrations, and preserve active structures of proteins and nucleic acids [3]. In consequence, these bacteria need proper mechanisms of osmotic adaptation and ways to accumulate osmotically active compatible solutes up to several molar concentrations at the extremes.

Limitation to protect cell structures and metabolism is given by the compatibility of the solutes and the ability to accumulate to high or extremely high, several molar concentrations inside the cell. Glycine betaine (in some cyanobacteria also glutamate betaine) and ectoine (also hydroxyectoine) are the top candidates for this function in bacteria. Glycine betaine (hereafter "betaine") accumulation is widespread among phototrophic and 
chemotrophic eubacteria [4-8]. Ectoine was first identified as a compatible solute in the extreme halophilic Halorhodospira halochloris [9] and was later shown to be widely distributed among marine and halophilic eubacteria [10]. Though a number of other solutes are accumulated in bacteria in response to osmotic stress, these can provide protection only at low to moderate osmotic stress. Such compounds include sugars such as trehalose and sucrose, amino acids in particular glutamate, glucosyl glycerol, N-acetyl-glutaminyl glutamine amide, N-carbamoyl-glutamine amide, and others [6,7,11-13]. Basically, the accumulation can be achieved by uptake from the environment or by biosynthesis.

Betaine biosynthesis can be achieved by three consecutive methylation steps from glycine and includes the formation of monomethylglycine (sarcosine) and dimethylglycine as intermediates. In most of the bacteria studied, these enzymes are encoded by two genes and have overlapping enzymatic activities. In Halorhodospira halochloris, the first enzyme (glycine and sarcosine methyltransferase GMT) catalyzes the formation of monomethylglycine and dimethylglycine and the second one (dimethylglycine methyltransferase DMT) catalyzes the methylations to dimethylglycine and betaine [14,15]. In the halophilic cyanobacterium Aphanothece halophytica, the second enzyme specifically catalyzes the methylation of dimethylglycine [16]. In Actinopolyspora halophila, the two genes are fused, showing corresponding sequence homologies to the two genes in Halorhodospira halochloris [14].

An alternative route of betaine biosynthesis starts from choline and oxidizes this compound in two steps to betaine, catalyzed by choline dehydrogenase (BetA) and betaine aldehyde dehydrogenase (BetB). This route is widely distributed among bacteria but requires the external presence and uptake of choline. One possible uptake system is the high-affinity secondary transporter Bet $\mathrm{T}$, considered to be a specific choline transporter in E. coli [17] and a betaine transporter in Aphanothece halophytica [18]. In E. coli, the betT gene, together with a regulatory betI gene, is included in the bet gene cluster.

The biosynthesis of ectoine, which was first identified in the extreme halophilic phototrophic bacterium Halorhodospira halochloris [9], starts from aspartate. Aspartate is activated to L-aspartate-phosphate (Ask_ect) and then reduced to L-aspartate- $\beta$-semialdehyde (Asd), followed by a transamination (with glutamate or alanine as donor of the amino group) to L-diaminobutyric acid (EctB), acetylation of the amino group to $\mathrm{N}$-acetyldiaminobutyric acid (EctA), and finally ring closure (EctC) to form ectoine, as shown for Halorhodospira halophila and Halomonas elongata $[19,20]$. Genes responsible for ectoine biosynthesis and their osmotically regulated expression were first identified in Marinococcus halophilus [21]. The oxidation of ectoine to hydroxyectoine, which was first demonstrated in Streptomyces parvulus [22], turned out to be common to many Actinobacteria. The hydroxylation of ectoine $(\mathrm{EctD})$ is strongly dependent on the presence of molecular oxygen and is accompanied by the oxidative decarboxylation of oxoglutarate forming $\mathrm{CO}_{2}$ and succinate [23]. While the ask_ect gene, which encodes a specific aspartate kinase not underlying the feedback control of threonine [24,25], is often included in the ect gene cluster, asd usually is at a different locus in the genome. The coexpression of ask_ect together with the osmotically induced gene cluster ect $A B C$, ensures optimal supply of the precursor L-aspartate- $\beta$-semialdehyde under osmotic stress conditions. Aspects of ectoine and hydroxyectoine biosynthesis were recently reviewed by Czech et al. [10].

Osmotic adaptation can also be achieved by uptake of osmolytes rather than biosynthesis. Provided that such solutes are available in the environment, uptake generally is the favored way, because it is far less energetically expensive than de novo synthesis. Laboratory culture media with complex carbon sources (e.g., proteose peptone and yeast extract), often contain these compounds. In such media, betaine was accumulated to high levels exceeding $1 \mathrm{M}$ concentrations by a number of salt-tolerant chemoheterotrophic bacteria isolated from hypersaline soils [5]. Additionally, a number of phototrophic green and purple sulfur bacteria are able to take up and accumulate betaine but are incapable of its biosynthesis [13]. In nature, such situations can occur, whenever large decaying biomass is accumulated and betaine or choline becomes available, leaking from living cells or released upon cell lysis. Under such conditions, which are likely found in microbial mats, 
uptake might become an important strategy to accumulate compatible solutes, although dependent on biosynthesis as their primary producers. Uptake systems for betaine, choline, and ectoine are found in numerous bacteria, many of which are unable to biosynthesize these molecules. Best known is a widely distributed transport system first identified in the transport of proline ProU (ProVWX), which has low affinity to choline and also transports glycine betaine, proline betaine, carnitine, and ectoine $[26,27]$. Another betaine transport system is OpuA. Both of these systems are $A B C$ type transport systems and include binding proteins for the substrate and for ATP and a permease (ProVWX, OpuAA,AB,AC). Several more other transport systems for osmolytes are known (see [27]). Of these, OpuD is a single-component secondary transporter for betaine. BetT might also be active in betaine transport as found in Aphanothece halophytica [18].

In the present study, we focused on the biosynthetic capability of phototrophic bacteria to produce betaine and ectoine, using genomic information available from new genome sequences and from databases. The genomic repertoire and the distribution of the studied biosynthesis pathways are related to salt responses of the bacteria to conclude on their requirements for environmental adaptation. In addition, the phylogeny of ectoine and betaine biosynthesis was studied by comparing sequences of glycine-sarcosine-methyltransferase (GMT) and diaminobutyrate-pyruvate aminotransferase (EctB) of phototrophic bacteria, together with selected chemotrophic bacteria.

\section{Materials and Methods}

\subsection{Cultivation and DNA Extraction}

Cells were grown in the appropriate media, as described for the purple sulfur bacteria $[28,29]$ and several groups of phototrophic nonsulfur purple bacteria [30]. Extraction of DNA was done as described earlier [31]. DNA from $2 \mathrm{~mL}$ of a freshly grown culture was extracted with the DNeasy ${ }^{\circledR}$ Blood\&Tissue Kit, according to the manufacturer's instructions (QIAgen, Hilden, Germany), including the pretreatment for Gram-positive bacteria (consisting of enzymatic lysis buffer, proteinase $\mathrm{K}$, and RNAse) and then dissolved in the TE-buffer. The extracted DNA was checked for quantity and quality by agarose gel electrophoresis with linear and double-stranded Lambda DNA used as control (Thermo Fisher Scientific, Waltham, MA, USA, Cat.No. SD0011). DNA was purified using a gel extraction procedure with the MoBio Ultra DNA Purification Kit (Cat.No. 12100-300).

\subsection{Sequencing and Assembly}

Sequencing of DNA and the assembly of sequences were done, as described earlier [31]. Samples were prepared with the Nextera ${ }^{\circledR}$ XT DNA Sample Preparation kit from Illumina, following the manufacturer's protocol. Afterwards, the samples were pooled and sequenced on the MiSeq using the MiSeq ${ }^{\circledR}$ Reagent Kit v3 600 cycles sequencing chemistry. The library was clustered to a density of approximately $1200 \mathrm{~K} / \mathrm{mm}^{2}$.

Read quality filtering was performed with Trimmomatic v0.36 [32]. Reads were scanned for residues of Illumina Nextera XT adapters. Quality trimming was conducted with a 5-base pairs (bp) sliding window, trimming the read once the average Phred quality score within this window dropped below 30. Reads with a minimum length of $21 \mathrm{bp}$ after quality trimming were retained. Single reads (i.e., reads with their mate deleted) were retained and included into downstream analysis. Reads were further checked for ambiguous base calls as well as for low complexity, employing the DUST algorithm [33]. They were filtered accordingly with an in-house R script in Microsoft R Open v3.3.2 (R Core Team 2016). Retained reads are referred to as 'filtered reads'. Filtered reads were preassembled with SPAdes v3.10.0 [34,35], using default k-mer lengths. Scaffolds $\geq 500$ bp of this pre-assembly were subjected to extension and second-round scaffolding with SSPACE standard v3.0 [36]. 


\subsection{Genome Annotation and Submission to GenBank}

Genome sequences were annotated by the "Rapid Annotation using Subsystem Technology" (RAST) [37]. Sequences of EctB, GMT, and ProW were retrieved from the annotated genomes using the RAST and The SEED Viewer provided by this platform [38,39], which also offered the option to search with gene/protein sequences within the annotated genomes. In addition, standard protein BLAST of the NCBI database was used with EctB and GMT sequences to retrieve additional protein sequences. All genome sequences were deposited in the GenBank database (Supplementary Table S4). Accession numbers of gene and genome sequences, together with species and strain designations as well as the corresponding higher taxonomic ranks, are included in Supplementary Tables S1-S4.

\subsection{Phylogenetic Sequence Analyses}

For phylogenetic analysis, protein sequences of GMT, EctB, and ProW were aligned using ClustalX version 2.1 [40] and the trees were calculated by the neighbor-joining (NJ) method with correction for multiple substitutions, according to ClustalX [41]. NJ plot was used to draw the phylogenetic trees expressed in the Newick phylogenetic tree format [42]. The tree topologies were evaluated with bootstrap analyses, based on 1000 replicates and the values are indicated in the trees.

\section{Results and Discussion}

\subsection{Osmotic Adaptation in Phototrophic Bacteria}

According to genome analysis of representative phototrophic bacteria, the genetic repertoire and kind of possible responses to osmotic stress of these bacteria varies widely between the different groups and between freshwater, marine, and halophilic species. The genetic repertoire of all studied phototrophic bacteria is shown in Tables 1-3. While almost all marine and halophilic phototrophic bacteria can synthesize either betaine or ectoine or both, true freshwater bacteria lack the ability to synthesize betaine and ectoine. Often, they also lack the possibility of uptake of these osmolytes or their biosynthetic precursors, while marine and halophilic bacteria generally have this option. Obviously, biosynthesis or uptake of betaine more than that of ectoine is a prerequisite for their ability to thrive in marine and hypersaline habitats and to tolerate high salt concentrations. 


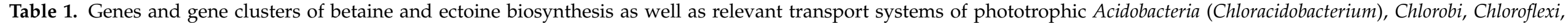

Cyanobacteria, Heliobacterium modesticaldum, Gemmatimonas phototrophica and Betaproteobacteria are shown together with salt responses and their systematic affiliation a,b,c.

\begin{tabular}{|c|c|c|c|c|c|c|c|c|}
\hline \multicolumn{9}{|c|}{ Gene Repertoire of Various Orders of Phototrophic Bacteria for Osmotic Adaptation } \\
\hline \multirow[t]{4}{*}{ Family } & \multirow[t]{4}{*}{ Species } & \multirow[t]{4}{*}{ Strain } & \multirow{4}{*}{$\begin{array}{c}\text { Salt } \\
\text { response }\end{array}$} & \multirow{3}{*}{$\begin{array}{c}\text { Betaine } \\
\text { from glycine } \\
\text { GMT-DMT }\end{array}$} & \multirow{3}{*}{$\begin{array}{l}\text { biosynthesis } \\
\text { from choline } \\
\text { betAB }\end{array}$} & \multicolumn{2}{|c|}{ Osmolyte transport } & \multirow{4}{*}{$\begin{array}{l}\text { proW1 } \\
\text { proW2 }\end{array}$} \\
\hline & & & & & & & & \\
\hline & & & & & & betT & opuA /opuC & \\
\hline & & & & & & & opuD & \\
\hline \multicolumn{9}{|c|}{ Acidobacteria/Acidobacteriales } \\
\hline Acidobacteriaceae & $\begin{array}{c}\text { Chloracidobacterium } \\
\text { thermophilum }\end{array}$ & B-G2 & $\mathrm{F}$ & o & o & o & o & o \\
\hline \multicolumn{9}{|c|}{ Chlorobi/Chlorobiales } \\
\hline Chlorobiaceae & $\begin{array}{l}\text { Chlorobaculum } \\
\text { thiosulfatophilum }\end{array}$ & DSM 249 & $\mathrm{~F}$ & o & o & o & o & $\mathrm{o}$ \\
\hline Chlorobiaceae & Chlorobium limicola & DSM 245 & $\mathrm{~F}$ & $\mathrm{o}$ & $\mathrm{o}$ & o & o & o \\
\hline Chlorobiaceae & $\begin{array}{l}\text { Chlorobium } \\
\text { phaeovibrioides }\end{array}$ & DSM 265 & $\mathrm{~F}$ & $\mathrm{o}$ & o & o & o & $\mathrm{o}$ \\
\hline Chlorobiaceae & $\begin{array}{l}\text { Chloroherpeton } \\
\text { thalassium }\end{array}$ & ATCC 35110 & M & GMT-DMT-betT & o & $\mathrm{o}$ & o & o \\
\hline Chlorobiaceae & $\begin{array}{l}\text { Prosthecochloris } \\
\text { aestuarii }\end{array}$ & DSM 271 & M & $\mathrm{o}$ & o & o & $\mathrm{o}$ & o \\
\hline \multicolumn{9}{|c|}{ Chloroflexi/Chloroflexales } \\
\hline Chloroflexaceae & Chloroflexus aggregans & DSM 9485 & $\mathrm{~F}$ & & $\mathrm{o}$ & & o & o \\
\hline Chloroflexaceae & $\begin{array}{l}\text { Chloroflexus } \\
\text { aurantiacus }\end{array}$ & J-10-fl & $\mathrm{F}$ & o & $\mathrm{o}$ & & $\mathrm{o}$ & $\mathrm{o}$ \\
\hline Roseiflexaceae & Roseiflexus castenholzii & DSM 13941 & $\mathrm{~F}$ & o & $\mathrm{o}$ & & opuCB-proXV & o \\
\hline Roseiflexaceae & Roseiflexus sp. & RS-1 & $\mathrm{F}$ & o & $\mathrm{o}$ & & opuCB-proXV & o \\
\hline \multicolumn{9}{|c|}{ Cyanobacteria/Synechococcales } \\
\hline Prochloraceae & $\begin{array}{l}\text { Prochlorococcus } \\
\text { marinus }\end{array}$ & MIT 9313 & M & GMT-DMTproVWX & o & o & o & o \\
\hline Synechococcaceae & Synechococcus species & WH8102 & M & GMT-DMTproVWX & $\mathrm{o}$ & $\mathrm{o}$ & o & o \\
\hline Synechococcaceae & Dactylococcopsis salina & PCC 8305 & $\mathrm{H}$ & GMT-DMT & $\mathrm{o}$ & o & $\mathrm{o}$ & W1 \\
\hline
\end{tabular}


Table 1. Cont

Gene Repertoire of Various Orders of Phototrophic Bacteria for Osmotic Adaptation

Cyanobacteria/Chroococcales

\begin{tabular}{|c|c|c|c|c|c|c|c|c|}
\hline \\
\hline Aphanothecaceae & $\begin{array}{l}\text { Halothece } \\
\text { sp./Aphanothece } \\
\text { halophytica }\end{array}$ & PCC 7418 & $\mathrm{H}$ & GMT-DMT & $\mathrm{o}$ & /betT/ & o & W1 \\
\hline Aphanothecaceae & $\begin{array}{l}\text { Euhalothece } \\
\text { natronophila }\end{array}$ & Z-M001 & $\mathrm{H}$ & GMT-DMT & $\mathrm{o}$ & /betT/ & o & W1 \\
\hline \multicolumn{9}{|c|}{ Firmicutes/Clostridiales } \\
\hline Heliobacteriaceae & $\begin{array}{l}\text { Heliobacterium } \\
\text { modesticaldum }\end{array}$ & Ice1 & $\mathrm{F}$ & o & $\mathrm{o}$ & $\mathrm{o}$ & o & o \\
\hline \multicolumn{9}{|c|}{ Gemmatimonadetes/Gemmatimonadales } \\
\hline \multicolumn{9}{|c|}{ Betaproteobacteria/Burkholderiales } \\
\hline Burkholderiaceae & $\begin{array}{l}\text { Polynucleobacter } \\
\text { duraquae }\end{array}$ & MWH-MoK4 & $\mathrm{F}$ & o & o & o & o & o \\
\hline Comamonadaceae & Rhodoferax antarcticus & DSM 24876 & $\mathrm{~F}$ & $\mathrm{o}$ & o & o & o & W2 \\
\hline Comamonadaceae & Rhodoferax fermentans & DSM 10138 & $\mathrm{~F}$ & o & o & o & opuD & $\mathrm{o}$ \\
\hline uncl. Burkholderiales & Rubrivivax gelatinosus & IL144 & $\mathrm{F}$ & o & $\mathrm{o}$ & o & opuD & o \\
\hline uncl. Burkholderiales & Rubrivivax gelatinosus & DSM 1709 & $\mathrm{~F}$ & o & o & o & opuD & $\mathrm{o}$ \\
\hline uncl. Burkholderiales & $\begin{array}{c}\text { Rubrivivax gelatinosus } \\
155\end{array}$ & DSM 149 & $\mathrm{~F}$ & o & $\mathrm{o}$ & $\mathrm{o}$ & opuD & $\mathrm{o}$ \\
\hline \multicolumn{9}{|c|}{ Betaproteobacteria/Rhodocyclales } \\
\hline Rhodocyclaceae & Rhodocyclus purpureus & TEM & $\mathrm{F}$ & o & $\mathrm{o}$ & o & o & o \\
\hline Rhodocyclaceae & Rhodocyclus tenuis & IM 230 & $\mathrm{~F}$ & o & $\mathrm{o}$ & o & o & $\mathrm{o}$ \\
\hline
\end{tabular}

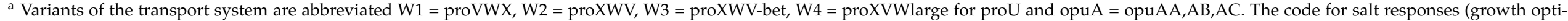

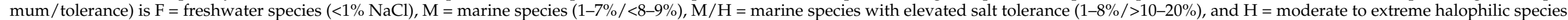

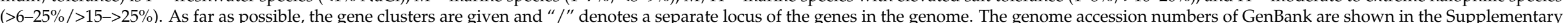

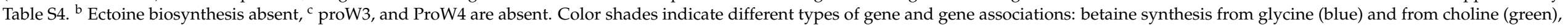
transport with betT (light-lila), opuA,C and D (shades of beige-brown), proU-W1 and W2 (shades of green); also marine (blue) and halophilic (rose-pink) growth response of the bacteria. 
Table 2. Genes and gene clusters of betaine and ectoine biosynthesis as well as relevant transport systems of phototrophic Alphaproteobacteria ${ }^{\text {a }}$.

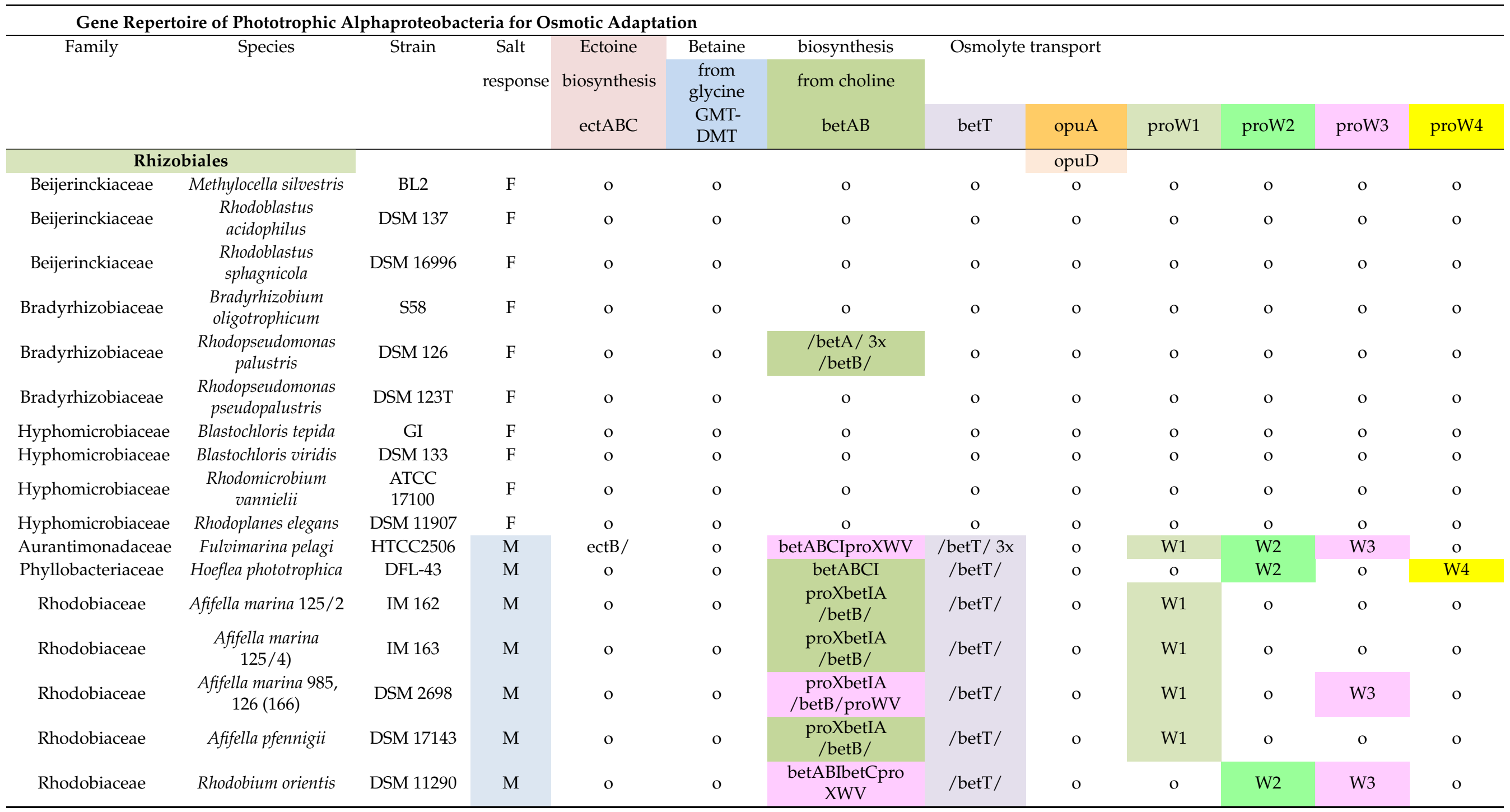


Table 2. Cont.

\begin{tabular}{|c|c|c|c|c|c|c|c|c|c|c|c|c|}
\hline \multicolumn{13}{|c|}{ Gene Repertoire of Phototrophic Alphaproteobacteria for Osmotic Adaptation } \\
\hline \multicolumn{13}{|c|}{ Rhodobacterales } \\
\hline Rhodobacteraceae & $\begin{array}{l}\text { Rhodobacter } \\
\text { capsulatus }\end{array}$ & SB 1003 & $\mathrm{~F}$ & o & o & betABIproXWV & & o & o & o & W3 & $\mathrm{o}$ \\
\hline Rhodobacteraceae & $\begin{array}{l}\text { Rhodobacter } \\
\text { sphaeroides }\end{array}$ & $\begin{array}{l}\text { ATCC } \\
17025\end{array}$ & F & $\mathrm{o}$ & $\mathrm{o}$ & betABIproXWV & & o & o & W2 & W3 & o \\
\hline Rhodobacteraceae & $\begin{array}{l}\text { Rhodobacter } \\
\text { veldkampii }\end{array}$ & DSM 11550 & $\mathrm{~F}$ & $\mathrm{o}$ & $\mathrm{o}$ & betABIproXWV & & o & o & W2 & W3 & W4 \\
\hline Rhodobacteraceae & $\begin{array}{c}\text { Rhodobaca } \\
\text { barguzinensis }\end{array}$ & DSM19920 & M & $\begin{array}{l}\text { ectRABCask- } \\
\text { ect }\end{array}$ & $\mathrm{o}$ & betAB>proXWV & /betT/ $2 \mathrm{x}$ & o & o & W2 & W3 & o \\
\hline Rhodobacteraceae & $\begin{array}{l}\text { Rhodobaculum } \\
\text { claviforme }\end{array}$ & GOR B7-4 & M & $\begin{array}{l}\text { ectRABCask- } \\
\text { ect }\end{array}$ & $\mathrm{o}$ & o & /betT/ $2 \mathrm{x}$ & o & o & o & $\mathrm{o}$ & o \\
\hline Rhodobacteraceae & $\begin{array}{l}\text { Rhodovulum } \\
\text { adriaticum }\end{array}$ & DSM2781 & M & $\begin{array}{l}\text { ectRABCask- } \\
\text { ect }\end{array}$ & $\mathrm{o}$ & o & /betT/ & o & o & W2 & $\mathrm{o}$ & o \\
\hline Rhodobacteraceae & Rhodovulum imhoffii & DSM 18064 & M & $\begin{array}{l}\text { ectRABCask- } \\
\text { ect }\end{array}$ & $\mathrm{o}$ & o & /betT/ $2 \mathrm{x}$ & o & o & o & $\mathrm{o}$ & o \\
\hline Rhodobacteraceae & $\begin{array}{l}\text { Rhodovulum } \\
\text { sulfidophilum }\end{array}$ & IM 196 & M & $\begin{array}{l}\text { ectRABCask- } \\
\text { ect }\end{array}$ & $\mathrm{o}$ & o & /betT/ & $\mathrm{o}$ & $\mathrm{o}$ & W2 & $\mathrm{o}$ & o \\
\hline Rhodobacteraceae & $\begin{array}{l}\text { Rhodovulum } \\
\text { sulfidophilum }\end{array}$ & DSM 2351 & M & $\begin{array}{l}\text { ectRABCask- } \\
\text { ect }\end{array}$ & $\mathrm{o}$ & o & /betT/ & $\mathrm{o}$ & o & W2 & $\mathrm{o}$ & o \\
\hline Rhodobacteraceae & $\begin{array}{l}\text { Rhodovulum } \\
\text { sulfidophilum }\end{array}$ & DSM 1374 & M & $\begin{array}{l}\text { ectRABCask- } \\
\text { ect }\end{array}$ & $\mathrm{o}$ & o & /betT/ & $\mathrm{o}$ & o & W2 & $\mathrm{o}$ & o \\
\hline Rhodobacteraceae & $\begin{array}{l}\text { Roseisalinus } \\
\text { antarcticus }\end{array}$ & DSM 11466 & M & $\begin{array}{l}\text { ectR-X- } \\
\text { ectABCask- } \\
\text { ect }\end{array}$ & $\mathrm{o}$ & $\begin{array}{l}\text { betABNCIpro } \\
\text { XWV/betAT }\end{array}$ & /betT/ $2 \mathrm{x}$ & $\mathrm{o}$ & o & o & W3 & o \\
\hline Rhodobacteraceae & Roseivivax isoporae & LMG 25204 & $\mathrm{M} / \mathrm{H}$ & $\begin{array}{l}\text { ectRABCask- } \\
\text { ect }\end{array}$ & $\mathrm{o}$ & $\begin{array}{c}\text { betABC } \\
/<\text { bet>proWX }\end{array}$ & /betT/ $4 \mathrm{x}$ & $\mathrm{o}$ & o & o & & o \\
\hline Rhodobacteraceae & $\begin{array}{l}\text { Roseivivax } \\
\text { halotolerans }\end{array}$ & JCM 10271 & $\mathrm{M} / \mathrm{H}$ & $\begin{array}{l}\text { ectRABCask- } \\
\text { ect }\end{array}$ & $\mathrm{o}$ & $\begin{array}{c}\text { betABC } \\
\text { / betI>proWV }\end{array}$ & $/ \operatorname{bet} \mathrm{T} / 3 \mathrm{x}$ & $\mathrm{O}$ & o & W2 & & o \\
\hline Rhodobacteraceae & $\begin{array}{l}\text { Roseivivax } \\
\text { halodurans }\end{array}$ & JCM 10272 & $\mathrm{M} / \mathrm{H}$ & $\begin{array}{l}\text { ectRABCask- } \\
\text { ect }\end{array}$ & $\begin{array}{l}\text { fusedMT- } \\
\text { MAT }\end{array}$ & $\begin{array}{l}\text { betABTC /be- } \\
\text { tAT/bet>proWX }\end{array}$ & /betT/3x & $\mathrm{o}$ & o & W2 & & o \\
\hline Rhodobacteraceae & Roseivivax roseus & DSM 23042 & $\mathrm{H}$ & $\begin{array}{l}\text { ectRABCask- } \\
\text { ect }\end{array}$ & $\begin{array}{l}\text { fusedMT- } \\
\text { MTHFR- } \\
\text { MS-MAT- } \\
\text { SAHase }\end{array}$ & $\begin{array}{c}\text { betABCIproX/ } \\
\text { proWV }\end{array}$ & /betT/ $5 \mathrm{x}$ & $\mathrm{o}$ & W1 & $\mathrm{o}$ & & W4 \\
\hline
\end{tabular}


Table 2. Cont.

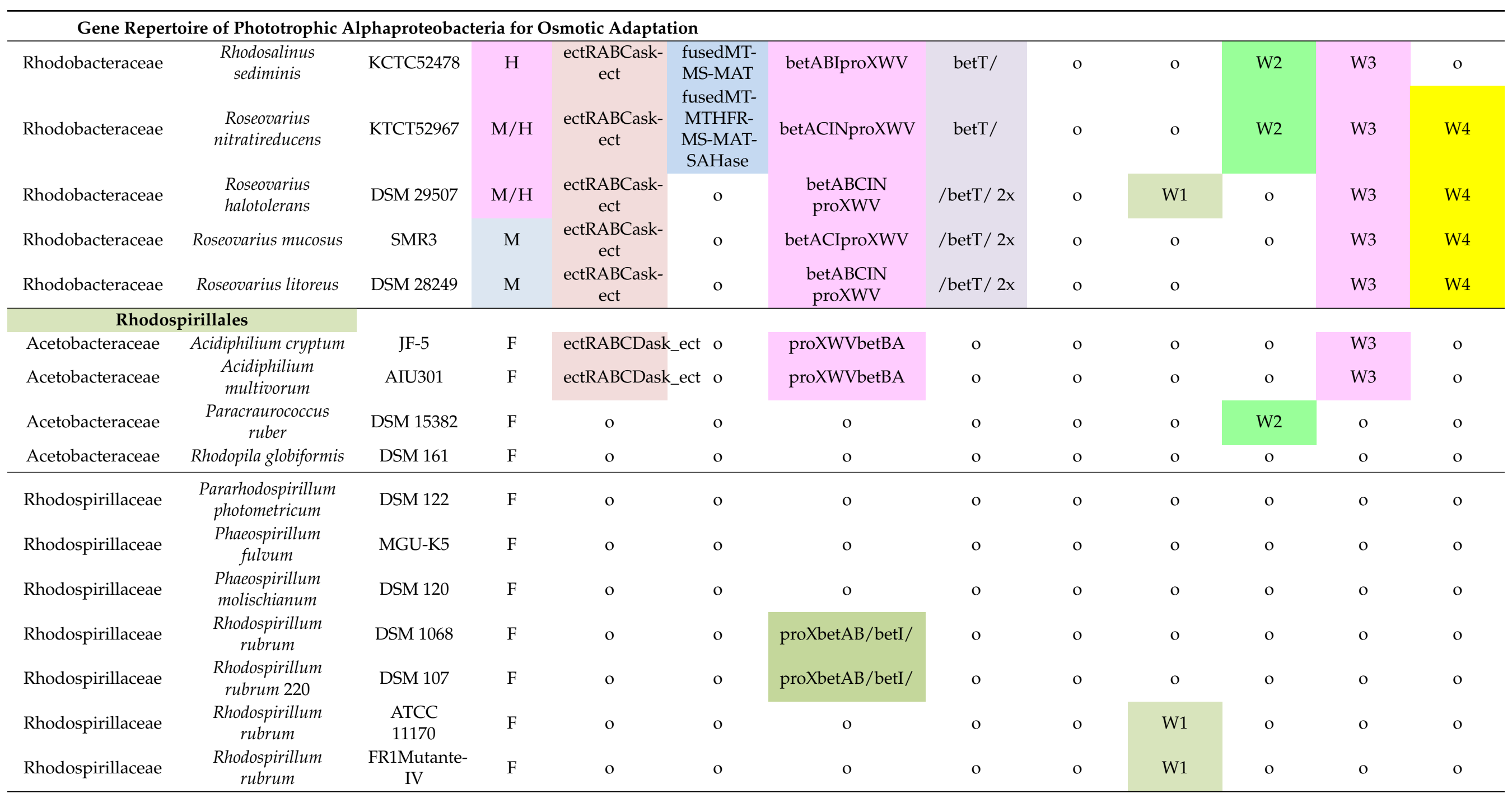


Table 2. Cont.

\section{Gene Repertoire of Phototrophic Alphaproteobacteria for Osmotic Adaptation}

\begin{tabular}{|c|c|c|c|c|c|c|c|c|c|c|c|c|}
\hline Rhodospirillaceae & \multirow{2}{*}{$\begin{array}{l}\text { Rhodovibrio } \\
\text { salinarum } \\
\text { Rhodovibrio } \\
\text { sodomensis }\end{array}$} & \multirow{2}{*}{$\begin{array}{l}\text { DSM } 9154 \\
\text { DSM } 9895\end{array}$} & \multirow{2}{*}{$\begin{array}{l}\mathrm{H} \\
\mathrm{H}\end{array}$} & \multirow{2}{*}{$\begin{array}{l}\text { ectBC } / 2 x \\
\text { ect } A \\
\text { ectBC } / 2 x \\
\text { ect } A\end{array}$} & \multirow{2}{*}{$\begin{array}{c}\text { GMT-B- } \\
\text { DMT- } \\
\text { MAT- } \\
\text { SAHase } \\
\text { GMT-B- } \\
\text { DMT- } \\
\text { MAT- } \\
\text { SAHase }\end{array}$} & \multirow{2}{*}{$\begin{array}{l}\text { betABIproX } \\
\text { betABIproX }\end{array}$} & \multirow{2}{*}{$\begin{array}{l}\text { betTproX } \\
\text { /betT/ 6x }\end{array}$} & \multicolumn{2}{|c|}{ proVWopuAC } & \multirow{2}{*}{$\begin{array}{l}\mathrm{o} \\
\mathrm{o} \\
\end{array}$} & \multirow{2}{*}{$\begin{array}{l}\mathrm{o} \\
\mathrm{o}\end{array}$} & \multirow{2}{*}{$\begin{array}{l}\text { W4 } \\
\text { W4 }\end{array}$} \\
\hline Rhodospirillaceae & & & & & & & & $\mathrm{o}$ & W1 & & & \\
\hline Rhodospirillaceae & $\begin{array}{l}\text { Caenispirillum } \\
\text { salinarum }\end{array}$ & AK4 & $\mathrm{M}$ & ectABCD/A/ & $\begin{array}{l}\text { fusedMT- } \\
\text { MAT }\end{array}$ & betABIproXWV & /betT/ & opuD & W1 & $\mathrm{o}$ & W3 & $\mathrm{o}$ \\
\hline Rhodospirillaceae & Rhodospira trueperi & $\begin{array}{l}\text { ATCC } \\
700224\end{array}$ & $\mathrm{M}$ & ectABC & $\begin{array}{l}\text { fusedMT- } \\
\text { MAT }\end{array}$ & o & $/$ betT/ $2 x$ & o & W1 & W2 & o & $\mathrm{o}$ \\
\hline Rhodospirillaceae & Roseospira marina & DSM 15113 & $\mathrm{M}$ & ectABC & $\begin{array}{c}\text { MAT- } \\
\text { fusedMT }\end{array}$ & betIBAproX & /betT/ $2 x$ & $\mathrm{o}$ & W1 & W2 & $\mathrm{o}$ & $\mathrm{o}$ \\
\hline Rhodospirillaceae & $\begin{array}{l}\text { Roseospira } \\
\text { navarrensis }\end{array}$ & DSM 15114 & $\mathrm{M}$ & ectABC & $\begin{array}{c}\text { MAT- } \\
\text { fusedMT }\end{array}$ & betIBAproX & /betT/ & o & W1 & $\mathrm{o}$ & o & W4 \\
\hline Rhodospirillaceae & $\begin{array}{l}\text { Roseospirillum } \\
\text { parvum }\end{array}$ & DSM 12498 & $\mathrm{M}$ & ectRABC & $\begin{array}{c}\text { MAT- } \\
\text { fusedMT }\end{array}$ & o & /betT/ $2 x$ & $\mathrm{o}$ & W1 & W2 & o & $\mathrm{o}$ \\
\hline \multicolumn{2}{|c|}{ Rhodothalassiales } & & & & & & & & & & & \\
\hline Rhodothalassiaceae & $\begin{array}{l}\text { Rhodothalassium } \\
\text { salexigens }\end{array}$ & IM 261 & $\mathrm{H}$ & $\mathrm{o}$ & $\begin{array}{l}\text { GMT- } \\
\text { DMT }\end{array}$ & $\mathrm{o}$ & /betT/ 3x & $\mathrm{o}$ & W1 & $\mathrm{o}$ & $\mathrm{o}$ & $\mathrm{o}$ \\
\hline Rhodothalassiaceae & $\begin{array}{l}\text { Rhodothalassium } \\
\text { salexigens }\end{array}$ & IM 265 & $\mathrm{H}$ & $\mathrm{o}$ & $\begin{array}{l}\text { GMT- } \\
\text { DMT }\end{array}$ & $\mathrm{o}$ & /betT/ 3x & $\mathrm{o}$ & W1 & $\mathrm{o}$ & $\mathrm{o}$ & $\mathrm{o}$ \\
\hline Rhodothalassiaceae & $\begin{array}{l}\text { Rhodothalassium } \\
\text { salexigens }\end{array}$ & DSM 2132 & $\mathrm{H}$ & $\mathrm{o}$ & $\begin{array}{l}\text { GMT- } \\
\text { DMT }\end{array}$ & $\mathrm{o}$ & /betT/ 3x & $\mathrm{o}$ & $\mathrm{o}$ & $\mathrm{o}$ & $\mathrm{o}$ & $\mathrm{o}$ \\
\hline \multicolumn{2}{|c|}{ Sphingomonadales } & & & & & & & & & & & \\
\hline Erythrobacteraceae & Erythrobacter litoralis & DSM 8509 & $\mathrm{M}$ & o & $\begin{array}{l}\text { GMT- } \\
\text { DMT }\end{array}$ & o & & o & o & o & o & $\mathrm{o}$ \\
\hline
\end{tabular}

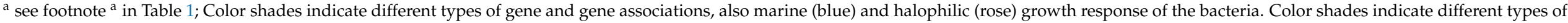

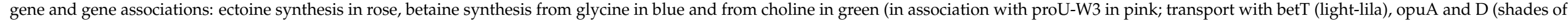

beige-brown), proU-W1 and proU-W2 shades of green, proU-W3 pink, proU-W4, yellow; also marine (blue) and halophilic (rose-pink) growth response of the bacteria. 
Table 3. Genes and gene clusters of betaine and ectoine biosynthesis as well as relevant transport systems of phototrophic Gammaproteobacteria ${ }^{\text {a,b }}$.

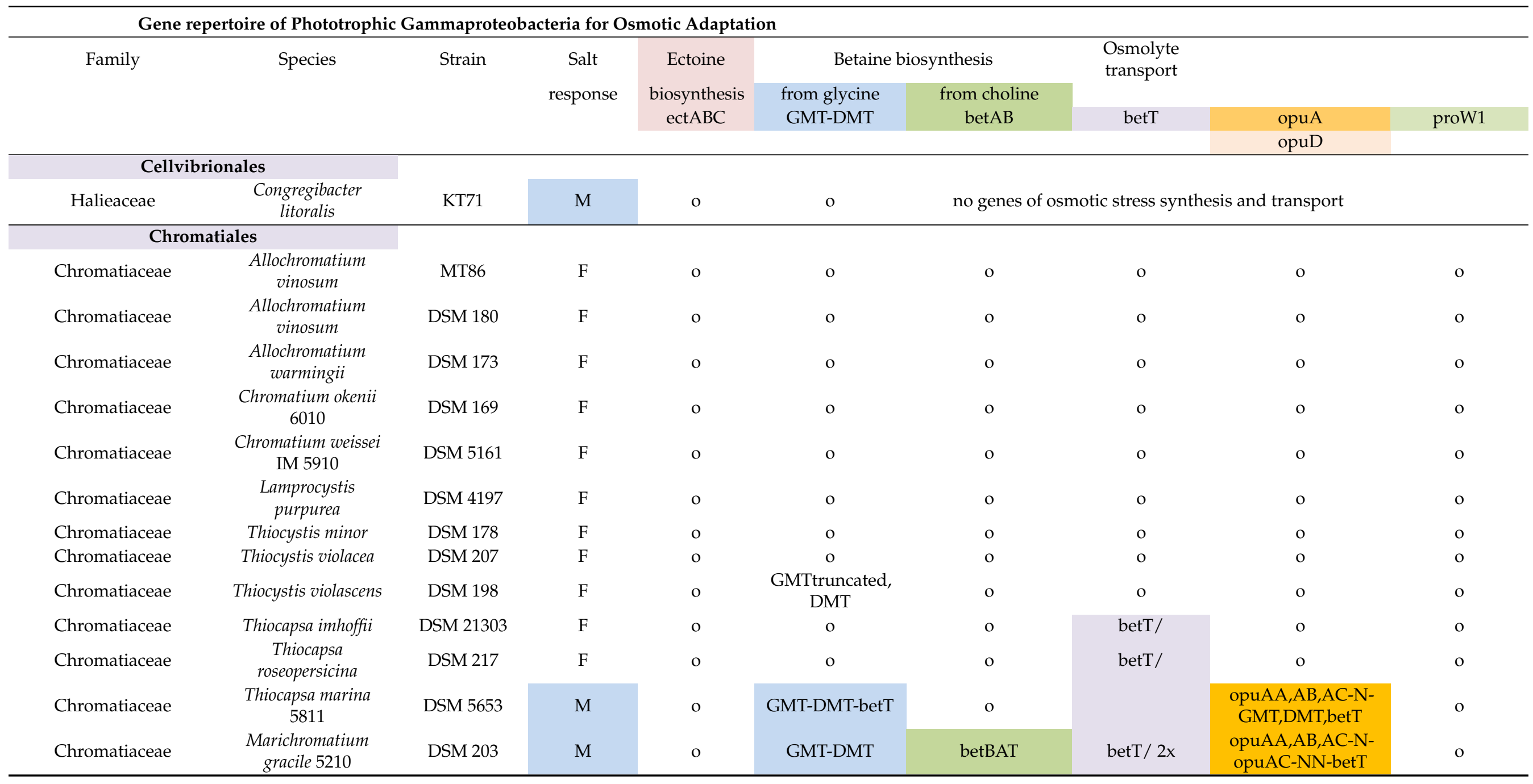


Table 3. Cont.

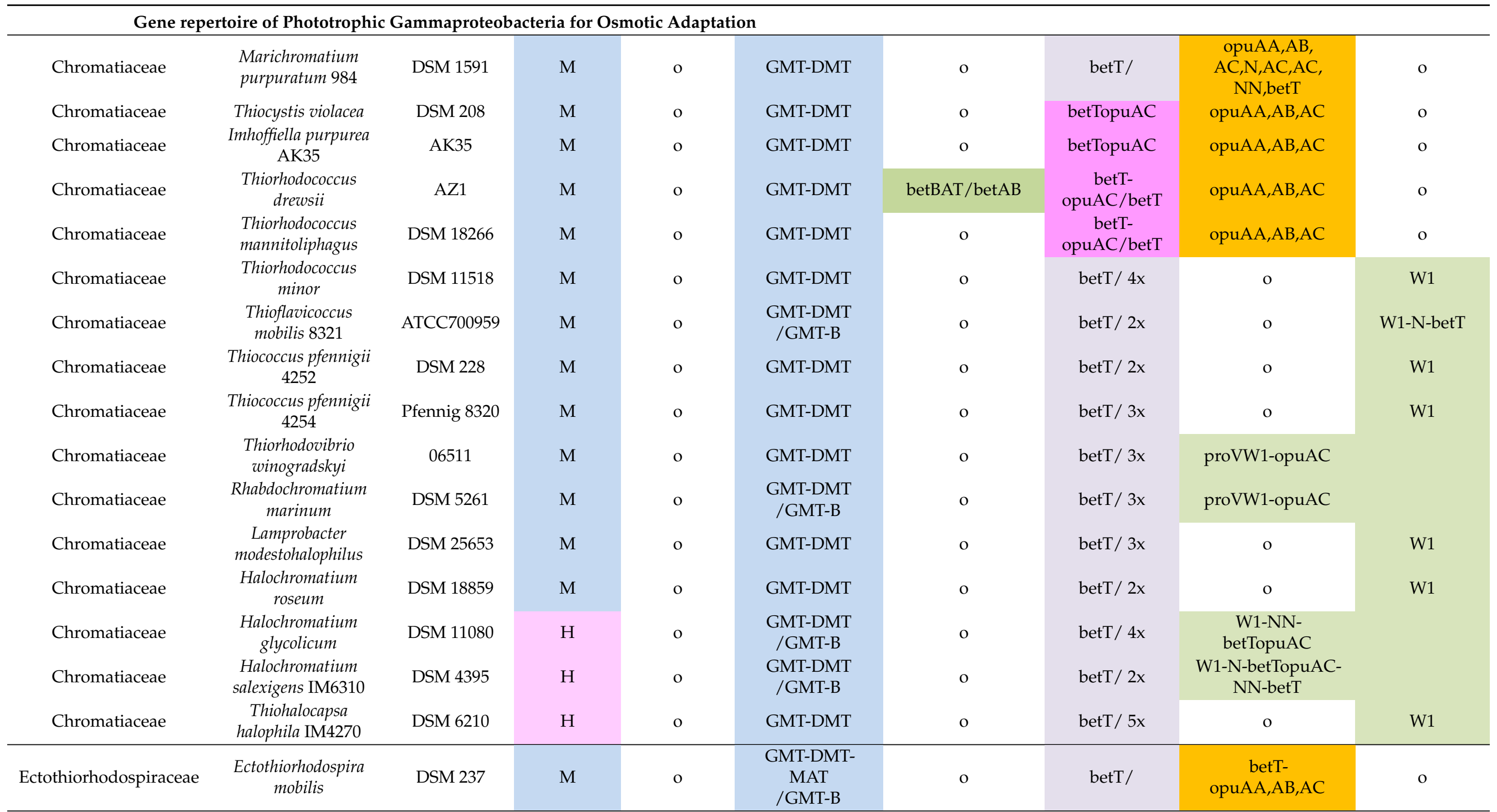


Table 3. Cont.

\begin{tabular}{|c|c|c|c|c|c|c|c|c|c|}
\hline \multicolumn{10}{|c|}{ Gene repertoire of Phototrophic Gammaproteobacteria for Osmotic Adaptation } \\
\hline Ectothiorhodospiraceae & $\begin{array}{c}\text { Ectothiorhodospira } \\
\text { marismortui }\end{array}$ & DSM 4180T & $\mathrm{M} / \mathrm{H}$ & o & $\begin{array}{l}\text { GMT-DMT- } \\
\text { MAT } \\
\text { /GMT-B }\end{array}$ & o & betT/ & $\begin{array}{c}\text { betT- } \\
\text { opuAA,AB,AC }\end{array}$ & o \\
\hline Ectothiorhodospiraceae & $\begin{array}{c}\text { Ectothiorhodospira } \\
\text { marina }\end{array}$ & DSM $241 \mathrm{~T}$ & $\mathrm{M} / \mathrm{H}$ & o & $\begin{array}{l}\text { GMT-DMT- } \\
\text { MAT } \\
\text { /GMT-B }\end{array}$ & betABIproX & betT & $\begin{array}{c}\text { betT-opuAA, } \\
\text { AB,AC }\end{array}$ & $\mathrm{O}$ \\
\hline Ectothiorhodospiraceae & $\begin{array}{c}\text { Ectothiorhodospira } \\
\text { haloalkaliphila }\end{array}$ & ATCC 51935 & $\mathrm{M} / \mathrm{H}$ & o & $\begin{array}{c}\text { GMT-DMT- } \\
\text { MAT } \\
\text { /GMT-B }\end{array}$ & betABIproX & $\operatorname{bet} \mathrm{T} / 2 \mathrm{x}$ & $\begin{array}{c}\text { betT-opuAA, } \\
\text { AB,AC }\end{array}$ & OpuD \\
\hline Ectothiorhodospiraceae & $\begin{array}{l}\text { Ectothiorhodospira } \\
\text { sp. }\end{array}$ & BSL-9 & M & o & $\begin{array}{c}\text { GMT-DMT- } \\
\text { MAT } \\
\text { /GMT-B }\end{array}$ & betABIproX & $\operatorname{bet} \mathrm{T} /$ & $\begin{array}{c}\text { betT- } \\
\text { opuAA,AB,AC }\end{array}$ & o \\
\hline Ectothiorhodospiraceae & $\begin{array}{c}\text { Ectothiorhodospira } \\
\text { shaposhnikovii }\end{array}$ & DSM 243 & M & ectB/ & $\begin{array}{l}\text { GMT-DMT- } \\
\text { MAT }\end{array}$ & betABIproX & & $\begin{array}{c}\text { betT- } \\
\text { opuAA,AB,AC }\end{array}$ & o \\
\hline Ectothiorhodospiraceae & $\begin{array}{c}\text { Ectothiorhodospira } \\
\text { magna B7-7 }\end{array}$ & DSM 22250 & M & o & $\mathrm{o}$ & o & & $\begin{array}{c}\text { betT- } \\
\text { opuAA,AB,AC }\end{array}$ & o \\
\hline Ectothiorhodospiraceae & $\begin{array}{c}\text { Ectothiorhodosinus } \\
\text { mongolicus M9 }\end{array}$ & DSM 15479 & M & $\mathrm{o}$ & $\mathrm{o}$ & o & betT/ & $\mathrm{o}$ & W1 \\
\hline Ectothiorhodospiraceae & $\begin{array}{l}\text { Halorhodospira } \\
\text { abdelmalekii }\end{array}$ & DSM 2110 & $\mathrm{H}$ & ectAB/C & $\begin{array}{c}\text { GMT-DMT- } \\
\text { MAT-SAHase- } \\
\text { MTHFR }\end{array}$ & $\mathrm{o}$ & see proU & opuD/ $2 x$ & W1-betT \\
\hline Ectothiorhodospiraceae & $\begin{array}{l}\text { Halorhodospira } \\
\text { halochloris }\end{array}$ & DSM 1059 & $\mathrm{H}$ & ectABC & $\begin{array}{c}\text { GMT-DMT- } \\
\text { MAT-SAHase- } \\
\text { MTHFR }\end{array}$ & o & $\operatorname{bet} T / 2 x$ & opuD & o \\
\hline Ectothiorhodospiraceae & $\begin{array}{l}\text { Halorhodospira } \\
\text { halophila }\end{array}$ & IM 9626 & $\mathrm{H}$ & ectABC & $\begin{array}{c}\text { GMT-DMT- } \\
\text { MAT-SAHase- } \\
\text { MTHFR/GMT- } \\
\text { B }\end{array}$ & $\mathrm{o}$ & $\operatorname{bet} T / 5 x$ & opuD & W1 \\
\hline Ectothiorhodospiraceae & $\begin{array}{l}\text { Halorhodospira } \\
\text { halophila SL1 }\end{array}$ & DSM 244 & $\mathrm{H}$ & ectABC & $\begin{array}{c}\text { GMT-DMT- } \\
\text { MAT-SAHase- } \\
\text { MTHFR/GMT- } \\
\text { B }\end{array}$ & o & $\operatorname{bet} \mathrm{T} / 4 \mathrm{x}$ & opuD & W1-N-betT \\
\hline
\end{tabular}


Table 3. Cont.

Gene repertoire of Phototrophic Gammaproteobacteria for Osmotic Adaptation

\begin{tabular}{|c|c|c|c|c|c|c|c|c|c|}
\hline Ectothiorhodospiraceae & $\begin{array}{c}\text { Halorhodospira } \\
\text { halophila D }\end{array}$ & IM 9620 & $\mathrm{H}$ & ectABC & $\begin{array}{c}\text { GMT-DMT- } \\
\text { MAT-SAHase- } \\
\text { MTHFR/GMT- } \\
\text { B }\end{array}$ & $\mathrm{o}$ & $\operatorname{bet} T / 5 x$ & opuD & W1-N-betT \\
\hline Ectothiorhodospiraceae & $\begin{array}{l}\text { Halorhodospira } \\
\text { halophila } 51 / 3\end{array}$ & IM 9630 & $\mathrm{H}$ & ectABC & $\begin{array}{c}\text { GMT-DMT- } \\
\text { MAT-SAHase- } \\
\text { MTHFR/GMT- } \\
\text { B }\end{array}$ & $\mathrm{o}$ & $\operatorname{bet} T / 5 x$ & opuD & W1 \\
\hline Ectothiorhodospiraceae & $\begin{array}{c}\text { Halorhodospira } \\
\text { neutriphila }\end{array}$ & DSM 15116 & $\mathrm{H}$ & ectABC & $\begin{array}{c}\text { GMT-DMT- } \\
\text { MAT-SAHase- } \\
\text { MTHFR/GMT- } \\
\text { B }\end{array}$ & $\mathrm{O}$ & $\operatorname{betT/3x}$ & $\mathrm{o}$ & W1 \\
\hline
\end{tabular}

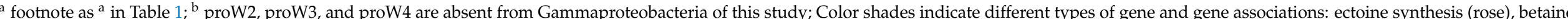

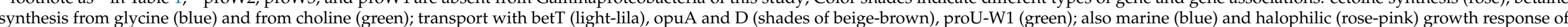
synthesis from
the bacteria. 
The ability to produce betaine or ectoine from the currently known routes is absent from the freshwater bacteria examined here, which include Heliobacteria, Chloracidobacterium, Chloroflexi, and the majority of Cyanobacteria and Chlorobiaceae, as well as phototrophic Betaproteobacteria (Table 1). Most of these bacteria also lack corresponding transport systems. Both pathways are also absent from the phylogenetic groups of freshwater phototrophic species of Rhizobiales, Acetobacteraceae, Rhodospirillaceae, Betaproteobacteria, and Chromatiaceae (Tables 1-3). In all freshwater bacteria that lack any of the options to accumulate betaine or ectoine, a limited osmotic adaptation might be achieved by accumulation of sugars, in particular trehalose and sucrose or glucosylglycerol, but also N-acetyl-glutaminylglutamine amide and N-carbamoyl-L-glutamine amide (Severin et al., 1992). Even potassium glutamate to some extent might contribute to osmotic adaptation $[1,6,7]$.

\subsubsection{Cyanobacteria}

It was demonstrated that the salt-tolerance of Cyanobacteria was clearly related to the compatible solutes accumulated, those of the lowest tolerance (freshwater strains growing below $0.7 \mathrm{M} \mathrm{NaCl}$ ) accumulate sucrose and trehalose, those of moderate tolerance (marine strains growing up to $1.8 \mathrm{M} \mathrm{NaCl}$ ) accumulate glucosylglycerol, and those with the highest tolerance (strains of marine and hypersaline origin, in great majority classified as Synechococcus strains) accumulate glycine betaine or glutamate betaine [11]. Apparently, the majority of cyanobacteria adapted to marine environments count on glucosylglycerol as osmoticum [43-45]. The formation of a fused molecule with glycerol (glucosyl glycerol) as a component appears to be a clever strategy to keep at least, in part, the excellent compatible nature of glycerol but reduce leakage through the cell membrane. Those Cyanobacteria originating from salt lakes and hypersaline ponds (tolerance of $>20 \% \mathrm{NaCl}$ ) accumulate betaine, which apparently is essential to provide sufficient protection at moderately and extremely high salt concentrations [11].

Betaine biosynthesis is found in two major phylogenetic branches of Cyanobacteria, but ectoine biosynthesis is absent (Table 1, Figure 1). One branch is formed by Aphanothece halophytica (Halothece PCC7418), together with other Chroococcales. Aphanothece halophytica is a characteristic inhabitant of hypersaline environments and among the most halotolerant of Cyanobacteria. A gene cluster of the two methyltransferases (GMT and DMT) is present in these bacteria (Table 1). The BetT present in Aphanothece halophytica, which lacks cholinedependent betaine synthesis, is characterized as a specific transporter of betaine [18]. A second major branch of Cyanobacteria includes representatives of the heterogeneous groups of the Synechococccus and Prochlorococcus species and is phylogenetically quite distinct from the first branch (Figure 1). These Cyanobacteria have proXWV genes included in a cluster with GMT and DMT genes (Table 1).

The two groups are also distinguished by significant difference in the $G+C$ content of the DNA. Representative strains of the Prochlorococcus group have a $\mathrm{G}+\mathrm{C}$ content near 50 mol\% for the Prochlorococcus marinus (strain MIT9313: 50.7 and strain MIT9303: 50.0\%) and near 59\% for Synechococcus (strain WH8102: 59.4\% and strain WH8103: 59.5\%). Much lower values are present in the Halothece/Aphanothece group: $42.9 \mathrm{~mol} \%$ in Aphanothece halophytica, $41.1 \mathrm{~mol} \%$ in Euhalothece natronophila, and $42.4 \mathrm{~mol} \%$ in Dactylococcopsis salina. Although systematically assigned to the Synechococcales, Dactylococcopsis salina fits very well into the Halothece group, according to the gene repertoire and the phylogeny of the GMT sequence (Figure 1, Table 1 ) as well as the $G+C$ content, which puts a question mark to its current taxonomic affiliation. 


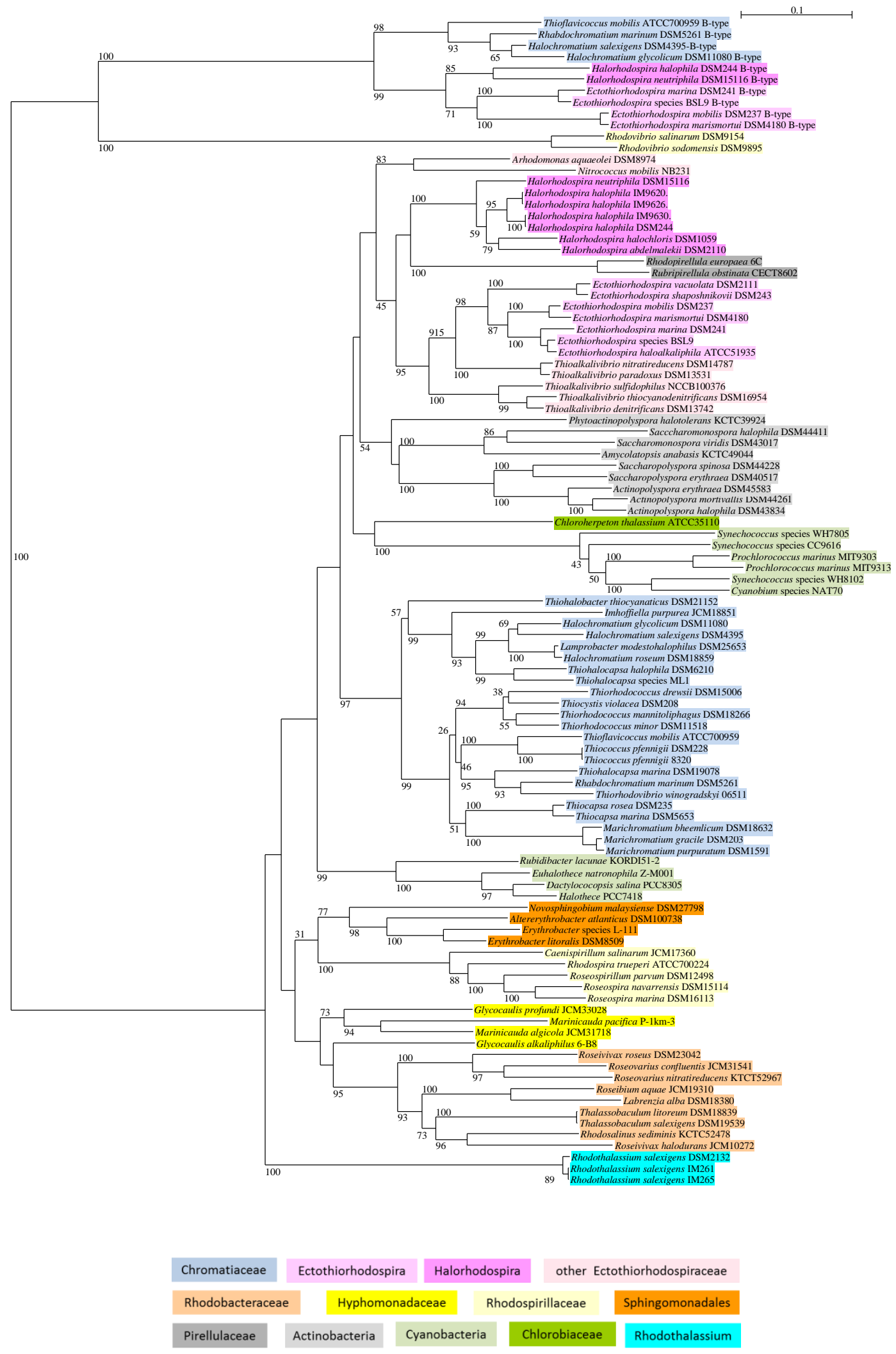

Figure 1. The phylogeny of betaine biosynthesis based on the sequences of glycine/sarcosine methyltransferase GMT is shown in a neighbor-joining tree. Sequences and gene bank accession numbers are shown in the Supplementary Table S1. Bootstrap values expressed as percentages of 1000 replications are given the branches. The bar indicates an evolutionary distance of 0.1 . The following color code highlights the different systematic groups. 


\subsubsection{Chlorobiaceae}

As most of the green sulfur bacteria thrive in freshwater habitats, it is not surprising that they lack possibilities of synthesis of betaine and ectoine. The marine Chloroherpeton thalassium is the only one that can produce betaine from glycine (Table 1 and Figure 1). However, members of the genus Prosthecochloris and in particular Prosthecochloris aestuarii are also regularly found in brackish and marine coastal or saline habitats. They might cope with marine concentrations of salt by accumulation of trehalose, as shown to occur in Prosthecochloris vibrioformis DSM 260 (Pfennig 6030) and Chlorobaculum thiosulfatophilum DSM 249 (Pfennig 6230) [13]. If grown in marine media supplied with betaine, they can also accumulate the betaine [13]. Therefore, they have limited possibilities to cope with salt stress by accumulation of trehalose and uptake of betaine from the environment, to thrive at elevated salt concentrations. It is expected that they take advantage of betaine uptake when occurring in hypersaline habitats. A gene cluster annotated as proVopuAB, $A C$ in Prosthecochloris vibrioformis DSM 260 (Table 1) presumably is a betaine transport system. The sequence of OpuAB is clearly distinct from those found in the Chromatiaceae and Ectothiorhodospira species, as well as from the ProW sequences found in other Chromatiaceae and Halorhodospira species and its ProV sequence is an outsider of the OpuAA branch (data not shown). This indicates that components of the transport system of Prosthecochloris vibrioformis might be related to an ancient ancestor of both the OpuA and the ProU transport systems, both of which might have evolved from a similar ancient ancestor. It would be interesting to study their catalytic properties and the evolutionary path of both systems.

\subsubsection{Chloroflexi}

Genes for the synthesis of ectoine and betaine were not found in the Chloroflexus and Roseiflexus species (Table 1). Additionally, transport systems for osmotica are absent from the Chloroflexus species, which characterizes them as strict freshwater bacteria. An ABC transport system (annotated as opuCBproXV and an $\mathrm{ABC}$ transport protein) found in the Roseiflexus castenholzii and Roseiflexus species RS-1 (Table 1) might as well represent an ancient evolutionary form of osmolyte transport and betaine uptake from the environment. Thereby, the Roseiflexus species might gain limited possibility for osmotic adaptation. As these bacteria are among the oldest mat-forming phototrophic bacteria and Roseiflexus might be able to take up betaine or other osmolytes, they or relatives thereof are expected to be found in marine microbial mats. It would be interesting to see, whether marine relatives have possibilities of compatible solute biosynthesis. The species known and characterized so far are expected to have lost such possibilities.

\subsubsection{Marine Rhizobiales}

Freshwater Rhizobiales (species of Rhodoblastus, Rhodopseudomonas, Blastochloris, Rhodomicrobium, and Rhodoplanes) lack both, biosynthesis genes for ectoine and betaine (from choline and glycine) as well as transport systems for these osmolytes (Table 2). In a group of marine Rhizobiales (Fulvimarina pelagi, Hoeflea phototrophica, Rhodobium orientis, Afifella species), the choline-dependent biosynthesis of betaine (BetABI) and a BetT transporter are present (Table 2). In addition, one or more copies/versions of the ProU system are found. Therefore, osmotic adaptation of these bacteria to the marine environment can be achieved by uptake of betaine or choline. In the absence of these compounds in the environment, other compatible solutes might be accumulated. For Afifella marina (formerly Rhodopseudomonas marina), the accumulation of trehalose was demonstrated [12].

\subsubsection{Marine and Halotolerant Rhodobacteraceae}

The Rhodobacteraceae include freshwater, marine and halophilic species. With the exception of the freshwater Rhodobacter species, all of them have a complete gene cluster for ectoine biosynthesis (ectRectABCask-ect). In addition, the extremely halotolerant Roseivivax halodurans, Roseivivax roseus, Rhodosalinus sediminis, and Roseovarius nitratireducens (not Roseivivax halotolerans and Roseovarius halotolerans) have genes of betaine biosynthesis from 
glycine, with gene clusters of varying composition (Table 2). In these bacteria, the GMT and DMT methyltransferase genes are fused, as in some of the halophilic Rhodospirillaceae (see below). Most of the Rhodobacteraceae have several transport systems for osmolytes. All have the BetT transport system, some strains have multiple copies. With the exception of Rhodobaculum claviforme and Rhodovulum imhoffii, they have several ProU systems, which according to the ProW sequences are phylogenetically distinct (Table 2 and see below under Section 3.5).

\subsubsection{Acetobacteraceae}

Phototrophic Acetobacteraceae are freshwater bacteria. Rhodopila globiformis lacks possibilities of synthesis and transport of betaine and ectoine, and Paracraurococcus ruber depends on external supply of such compounds and on transport via a ProU system (type W2) for osmotic adaptation (Table 2). Acidiphilium species, however, can produce ectoine and hydroxyectoine and in addition have a ProU (type W3) uptake system associated with the genes of betaine biosynthesis from choline (proXWVbetBA). Acidiphilium species are adapted to life in acidic freshwater habitats and their acidophilic nature should preclude their development in neutral/basic marine habitats. Therefore, the accumulation of ectoine and possibly also betaine might play a role in adaptation to highly acidic conditions rather than to saline habitats.

\subsubsection{Marine and Halophilic Rhodospirillaceae}

Freshwater species of Rhodospirillaceae including species of Pararhodospirillum, Rhodospirillum, and Phaeospirillum lack ectoine and betaine biosynthesis (from glycine) and only some strains of Rhodospirillum rubrum can synthesize betaine from choline or have a ProU transport system (Table 2). On the other hand, marine and halophilic Rhodospirillaceae (Rhodospira, Rhodovibrio, Roseospira, Roseospirillum, and Caenispirillum species) are genomically well equipped with possibilities of osmotic adaptation. These species are adapted to moderately and extremely high salt concentrations. In particular, the Rhodovibrio species tolerate more than $3 \mathrm{M}$ (up to $20 \%$ ) $\mathrm{NaCl}$. All of them synthesize ectoine (Caenispirillum salinarum also hydroxyectoine) and betaine. With the exception of Rhodospira trueperi and Roseospirillum parvum, they can also transform choline to betaine (betABI). Different to other Rhodospirillaceae, in the Rhodovibrio species, the GMT and DMT genes are not fused and form a gene cluster with MAT and SHAase. Their GMT gene is the only example of a B-type GMT gene in Alphaproteobacteria, and the ectA gene is not included in an ectABC cluster, as in almost all other phototrophic bacteria producing ectoine. In addition to bet $T$ (multiple), marine Rhodospirillaceae have one or more ProU transport systems. These are related to the proVWX type W1 (proU of E. coli), proXWV (type W2), or proXVW (type W4) systems. In Caenispirillum salinarum, a type W3 ProW system is present (Table 2).

\subsubsection{Halophilic Rhodothalassium salexigens}

Rhodothalassium salexigens is a moderate halophilic and especially salt tolerant bacterium that grows at salt concentrations exceeding $3 \mathrm{M}(20 \% \mathrm{NaCl})$. The outstanding properties of Rhodothalassium salexigens as distinct from all other phototrophic Alphaproteobacteria are demonstrated by sequences of the $16 \mathrm{~S}$ rRNA gene and of the photosynthesis reaction center and bacteriochlorophyll biosynthesis genes [46]. These are in line with its recognition as a separate genus, family and order of the Alphaproteobacteria [47,48]. Ectoine biosynthesis is absent (Table 2). Betaine biosynthesis from glycine is possible and GMT sequences form a distinct lineage among those of the Alphaproteobacteria (Figure 1). In addition, BetT and a type W1 ProU transport systems are present.

\subsubsection{Chromatiaceae}

Freshwater Chromatiaceae including Chromatium, Allochromatium, and Thiocystis species lack betaine and ectoine biosynthesis and corresponding transport systems (Table 3), Marine and halophilic Chromatiaceae can synthesize betaine from glycine and have the 
BetT transport system, but lack ectoine biosynthesis. With the exception of Marichromatium gracile and Thiorhodococcus drewsii, betaine biosynthesis from choline is absent. The group of marine representatives including the Marichromatium, Thiorhodococcus, and Imhoffiella species, Thiocapsa marina and Thiocystis violacea DSM 208 has an opuA gene cluster, but lacks the ProW permease protein of ProU. An exception is Thiorhodococcus minor, which has a ProU (type W1) instead of the OpuA system (Table 3) like all other marine and halophilic Chromatiaceae.

\subsubsection{Ectothiorhodospiraceae}

According to phylogeny of $16 \mathrm{~S}$ rRNA and photosynthetic reaction center genes, the Ectothiorhodospira and Halorhodospira species form two clearly separated branches that might even require a separation at the family level [46]. This clear separation is also reflected in different options for osmotic adaptation and in different lineages of normal as well as B-type GMT sequences (Table 3, Figure 1, see Section 3.2.2).

The Ectothiorhodospira species lack ectoine biosynthesis, but can synthesize betaine from glycine (GMT-DMT-MAT), with the exception of Ectothiorhodospira mobilis and Ectothiorhodospira marismortui also from choline (betABIproX). They have a gene cluster including genes of the OpuA and BetT transport systems (betT-opuAA,AB,AC) and additional bet $T$ gene copies (except Ectothiorhodospira vacuolata and Ectothiorhodospira shaposhnikovii), but lack the otherwise common ProU transporter (Table 3). An exception is the Ectothiorhodospira magna, which obviously lacks the biosynthetic capabilities and entirely depends on the uptake of betaine and ectoine (betT-opuAA,AB,AC) (Table 3). Ectothiorhodosinus mongolicus and Thiorhodospira sibirica are exceptions among the Ectothiorhodospiraceae. While the first lacks genes for biosynthesis of betaine and ectoine and only has ProU (type W1) and Bet T transport systems, the latter has no annotated osmotic stress genes at all. This limits the possible adaptation to elevated salt concentrations and suggests that alternative mechanisms/solutes are used to cope with the salt in the environment. Sucrose, N-carbamoylL-glutamine amide, or $\mathrm{N}$-acetyl-glutaminylglutamine amide are possible candidates that were found to accumulate in other purple sulfur bacteria, though in marine and halophilic species, they are found only in addition to betaine [12].

The Halorhodospira species are the most halophilic and halotolerant phototrophic bacteria and can thrive even in saturated salt solutions [1,2]. All Halorhodospira species have complete gene clusters for ectoine (ect $A B C)$ and betaine biosynthesis from glycine, but lack genes for transformation of choline to glycine (Table 3). They are the only Gammaproteobacteria to include adenosylmethionine synthetase (MAT), adenosylhomocysteinase (SAHase) and 5,10-methylene tetrahydrofolate reductase (MTHFR) into a gene cluster, together with the two methyltransferase genes (GMT-DMT-MAT-SAHase-MTHFR). They are well equipped with the transport systems for osmolytes and have multiple copies of BetT, the secondary transporter OpuD (except Halorhodospira neutriphila) and the ProU (type W1) transport system (except Halorhodospira halochloris). These transport systems assure that osmolytes leaking out of the cells at very high, several molar cytoplasmic concentrations can be regained by the cells, and are not wasted to the environment. Therefore, it is assumed that the available transport systems are able to take up betaine and ectoine.

\subsection{Phylogeny of Glycine-Methyltransferase GMT}

The methyltransferases that transform glycine to betaine, glycine and sarcosine methyltransferase (GMT), and dimethylglycine methyltransferase (DMT) are present in a wide range of phototrophic bacteria, Alpha-, and Gammaproteobacteria, Cyanobacteria and green sulfur bacteria, as revealed by genome analysis using the SEED facility of the RAST platform [39]; shown in Tables 1-3. A phylogenetic tree of GMT methyltransferases, which in addition to phototrophic bacteria includes data from the genomes of chemotrophic bacteria as well as from BLAST searches, is shown in Figure 1. Though many of the deep branching points are poorly resolved and not supported by bootstrap values, it is obvious that the phylogeny of GMT is well depicted in a number of major phylogenetic branches. The phy- 
logenetic grouping correlates well with differences in the gene clusters involved in betaine biosynthesis (Figure 1). The following major groups and distinct phylogenetic lineages are recognized.

\subsubsection{Chromatiaceae}

Among the phototrophic Gammaproteobacteria, marine and halophilic phototrophic Chromatiaceae and Ectothiorhodospiraceae species have the ability to produce betaine from glycine. Marine and halophilic species encoding this pathway of betaine biosynthesis are found in different phylogenetic lineages with (a) the halophilic species of the genus Halochromatium, Lamprobacter modestohalophilus, Thiohalocapsa halophila forming one branch and (b) the marine species of Marichromatium, Thiocapsa, Thiorhodococcus, Thiorhodovibrio, and Thiocystis violacea DSM 208, Rhabdochromatium marinum, together with Thiococcus pfennigii and Thioflavicoccus mobilis, forming a second one (Figure 1). In both of these branches of Chromatiaceae, including the separate lineages of Thiohalobacter thiocyanaticus and Imhoffiella purpurea, just the two methyltransferases (GMT and DMT) form a distinct gene cluster (Table 3).

\subsubsection{Ectothiorhodospiraceae}

According to GMT sequences, species of Halorhodospira and Ectothiorhodospira form two clearly separated groups (Figure 1). In Ectothiorhodospira, species including Thioalkalivibrio nitratireducens and related species, GMT and DMT genes form a cluster together with the gene encoding S-adenosylmethionine synthetase (methionine adenosyl transferase, MAT), which is essential for performance of the methylation by providing the methyl donor S-adenosylmethionine. In the Halorhodospira species, in addition, the genes encoding S-adenosyl homocysteinase (SAHase) and 5,10-methylene tetrahydrofolate reductase (MTHFR) are included in this gene cluster (Table 3). The methionine synthase (MS) that completes the methionine cycle is located at a different location within the genome. The coordinated action of these enzymes is expected to allow optimal performance of betaine biosynthesis by providing the essential methyl groups and removing the byproduct S-adenosylhomocysteine, which strongly inhibits the reaction [15]. The chemotrophic Arhodomonas aquaeolei and Nitrococcus mobilis (only GMT-DMT cluster) form a distinct subbranch within the Ectothiorhodospiraceae.

There is a curiosity with the presence of a second additional single GMT gene within a few species of Chromatiales, which is phylogenetically distinct from the genes commonly found in other phototrophic bacteria, except the two Rhodovibrio species (Figure 1). We refer to these genes as the B-type methyltransferases in betaine biosynthesis, compared to the "common" system. GMT sequences of this B-type group form three lineages of phototrophic Gammaproteobacteria, (i) marine and halophilic Chromatiaceae species (Halochromatium salexigens, Halochromatium glycolicum, Rhabdochromatium marinum and Thioflavicoccus mobilis), (ii) Halorhodospira species (Halorhodospira halophila, Halorhodospira neutriphila), and (iii) Ectothiorhodospira species (Ectothiorhodospira mobilis, Ectothiorhodospira marismortui, Ectothiorhodospira marina) (Figure 1). In contrast, the B-type GMT genes of Rhodovibrio sodomensis and Rhodovibrio salinarum are the only ones for biosynthesis of betaine in these bacteria that are unique among Alphaproteobacteria. While this gene is included in a functional gene cluster and is quite likely active in the betaine synthesis of the Rhodovibrio species (GMT-DMT-MAT-SAHase), its role in the Chromatiales is unclear and it might represent an evolutionary relict or a backup.

\subsubsection{Cyanobacteria}

Clearly two distinct branches of common GMT sequences of betaine biosynthesis are found in Cyanobacteria (Figure 1). The most divergent branch in the tree is represented by the Prochlorococcus group, including Synechoccoccus WH8102 and Prochlorococcus marinus. The second major phylogenetic branch of Cyanobacteria, the Halothece/Aphanothece group, is represented by the most prominent member of halophilic Cyanobacteria, Aphanothece 
halophytica (Halothece PCC7418), and several Chroococcales, including Euhalothece natronophila and Rubidibacter lacunae, but also Dactylococcopsis salina, which might be misclassified as a member of the Synechococcales.

\subsubsection{Alphaproteobacteria}

The GMT sequences of Alphaproteobacteria represent a diverse major branch, which includes the species of Sphingomonadales, Rhodothalassiales, Rhodobacterales, and Rhodospirillales, but no Rhizobiales (Figure 1). The following distinct subbranches of Alphaproteobacteria are formed:

- Rhodospirillaceae, including Caenispirillum salinarum, Rhodospira trueperi, Roseospira navarrensis, Roseospira marina, and Roseospirillum parvum (but not the Rhodovibrio species) have a fused GMT/DMT gene of the methyltransferases included in a small cluster with S-adenosylmethionine synthase (MAT).

- Rhodothalassium salexigens, which represents the most distant line to all other Alphaproteobacteria, has a small gene cluster with just the two methyltransferases.

- Sphingomonadales include Novosphingobium malayensis, Erythrobacter litoralis, Altererythrobacter atlanticus; in Erythrobacter litoralis just the two methyltransferases form a small gene cluster.

- Hyphomonadaceae include the Glycocaulis and Marinicauda species with a small gene cluster of the two methyltransferases only.

- Rhodobacteraceae included in the study, as indicated in Figure 1, form a subbranch together with Thalassobaculum litoreum and Thalassobaculum salexigens (according to $16 \mathrm{~S}$ rRNA phylogeny forming a branch with the Oceanobaculum species at an almost equal distance to the Rhodobacteraceae and Rhodospirillaceae species; data not shown). A fused GMT/DMT gene is associated with the MAT gene in Roseivivax halodurans, with the MS-MAT genes in Rhodosalinus sediminis, and with the MTHFR-MS-MAT-SAHase genes in Roseivivax roseus and Roseivarius nitratireducens (Table 2).

\subsubsection{Actinobacteria}

The Actinobacteria are the only major group of chemotrophic bacteria that show betaine biosynthesis from glycine. They form a distinct branch distantly related to Chromatiales and Chloroherpeton (Figure 1). In Actinopolyspora halophila, for example, a fused GMT/DMT gene is included in a gene cluster with MAT, MTHFR, and SAHase (Table 4).

\subsubsection{Chlorobiaceae}

Among the green sulfur bacteria, betaine biosynthesis is found only in Chloroherpeton thalassium. The GMT sequence forms a separate line that associates distantly with those of the halophilic Chromatiales and Actinobacteria (Figure 1). Both methyltransferase genes are found in a small cluster together with the BetT transport system (Table 1).

\subsubsection{Pirellulaceae}

The two methyltransferases of betaine biosynthesis (GMT, DMT) are also found in the chemotrophic Rhodopirellula europaea and Rubripirellula obstinata (Pirellulaceae). Phylogenetically, these GMT sequences form a distinct branch distantly associated with Ectothiorhodospiraceae, though with low confidence. In Rhodopirellula europaea, the betT gene forms a cluster with the two methyltransferases (GMT-DMT-betT).

\subsection{Phylogeny of EctB}

The ability for ectoine biosynthesis is found in several phylogenetic distant lineages of anoxygenic phototrophic bacteria. Two major phylogenetic branches (type-1 and type-2 EctB sequences) can be distinguished, which also show differences in the ect gene cluster structure (Figure 2). 
Table 4. Ectoine and betaine biosynthesis of selected chemotrophic bacteria ${ }^{a}$.

\begin{tabular}{|c|c|c|c|c|c|}
\hline Family & Species & Strain & $\begin{array}{c}\text { Ectoine } \\
\text { biosynthesis } \\
\text { ectABC }\end{array}$ & $\begin{array}{l}\text { Betaine } \\
\text { from } \\
\text { glycine } \\
\text { GMT- } \\
\text { DMT }\end{array}$ & $\begin{array}{l}\text { biosynthesis } \\
\text { from choline } \\
\text { betAB }\end{array}$ \\
\hline \multicolumn{6}{|l|}{ Actinobacteria } \\
\hline Actinopolysporaceae & $\begin{array}{c}\text { Actinopolyspora } \\
\text { halophila }\end{array}$ & DSM 43834 & ectABC & $\begin{array}{l}\text { fusedMT- } \\
\text { MAT-o- } \\
\text { MS- } \\
\text { SAHase- } \\
\text { MTHFR }\end{array}$ & $\mathrm{o}$ \\
\hline Gordoniaceae & $\begin{array}{l}\text { Gordonia } \\
\text { alkanivorans }\end{array}$ & NBRC16433 & ectABC & $\mathrm{o}$ & betABT \\
\hline Mycobacteriaceae & $\begin{array}{l}\text { Mycolicibacterium } \\
\text { thermoresistibile }\end{array}$ & DSM 44167 & ectABCD & $\mathrm{o}$ & betA/betB \\
\hline Streptomycetaceae & $\begin{array}{l}\text { Streptomyces } \\
\text { clavuligerus }\end{array}$ & ATCC 27064 & ectABCD/AB & $\mathrm{o}$ & betAB/betI/betT \\
\hline \multicolumn{6}{|l|}{ Bacilli/Bacillales } \\
\hline Bacillaceae & $\begin{array}{c}\text { Halobacillus } \\
\text { halophilus }\end{array}$ & DSM 2266 & ectABC/D & $\mathrm{o}$ & betABbetIopuAC \\
\hline \multicolumn{6}{|c|}{ Proteobacteria/Alphaproteobacteria } \\
\hline Rhodobacteraceae & $\begin{array}{l}\text { Jannaschia } \\
\text { seosinensis }\end{array}$ & СЕСТ7799 & ectRectABCask-ect & $\mathrm{o}$ & proVWXbetICBA \\
\hline Rhodobacteraceae & $\begin{array}{l}\text { Maritimibacter } \\
\text { alkaliphilus }\end{array}$ & HTCC2654 & ectRectABCask-ect & $\mathrm{o}$ & proVWooXbetICBA \\
\hline Rhodobacteraceae & $\begin{array}{l}\text { Paracoccus } \\
\text { halophilus }\end{array}$ & JCM 14014 & ectRectABCask-ect & o & proVWXbetIBA \\
\hline Rhodobacteraceae & $\begin{array}{c}\text { Salipiger } \\
\text { bermudensis }\end{array}$ & HTCC2601 & ectRectABCask-ect & $\mathrm{o}$ & proVWXbetICBA \\
\hline Rhodobacteraceae & Thioclava pacifica & DSM 10166 & ectRectABCask-ect & $\mathrm{o}$ & proVWoXbetIBA \\
\hline Rhodospirillaceae & $\begin{array}{l}\text { Ferruginivarius } \\
\text { sediminum }\end{array}$ & WD2A32 & ectRectABC/B/C /D & $\mathrm{o}$ & proXbetIBA \\
\hline \multicolumn{6}{|c|}{ Proteobacteria/Betaproteobacteria } \\
\hline Alcaligenaceae & $\begin{array}{l}\text { Achromobacter } \\
\text { xylosoxidans }\end{array}$ & SOLR10 & ectRABCD & $\mathrm{o}$ & betA/betB \\
\hline Alcaligenaceae & Bordetella avium & $197 N$ & ectRABCD & o & betA/ \\
\hline Burkholderiaceae & $\begin{array}{l}\text { Paucimonas } \\
\text { limoigeni }\end{array}$ & DSM 7445 & ectRABCD & $\mathrm{o}$ & betA/ \\
\hline Oxalobacteraceae & $\begin{array}{l}\text { Herminiimonas } \\
\text { arsenicooxidans }\end{array}$ & DSM 17148 & ectRABCD & o & betA/ \\
\hline \multicolumn{6}{|c|}{ Proteobacteria/Gammaproteobacteria } \\
\hline Halomonadaceae & Halomonas elongata & DSM 2581 & ectABC/D & o & proXbetIBA \\
\hline Halomonadaceae & $\begin{array}{c}\text { Chromohalobacter } \\
\text { salexigens }\end{array}$ & DSM 3043 & ectABC/D & $\mathrm{o}$ & proXbetIBA \\
\hline Halomonadaceae & $\begin{array}{c}\text { Chromohalobacter } \\
\text { marismortui }\end{array}$ & DSM 6770 & $\operatorname{ect} A B C / D$ & $\mathrm{o}$ & proXbetIBA \\
\hline Haliaceae & Haliea salexigens & DSM 19537 & ectRectABCask-ect & $\mathrm{o}$ & betA/ \\
\hline Chromatiaceae & Nitrosococcus oceani & ATCC 19707 & $\begin{array}{c}\text { ectRCask- } \\
\text { ect/ectABD }\end{array}$ & $\mathrm{o}$ & betA/ \\
\hline Chromatiaceae & $\begin{array}{l}\text { Nitrosococcus } \\
\text { halophilus }\end{array}$ & Nc4 & $\begin{array}{l}\text { ectRCask- } \\
\text { ect/ectABD }\end{array}$ & $\mathrm{o}$ & $\mathrm{o}$ \\
\hline Hahellaceae & Hahella chejuensis & КСТС2396 & ectABCD & $\mathrm{o}$ & betIBAproXWV \\
\hline Oceanospirillaceae & $\begin{array}{l}\text { Marinomonas } \\
\text { mediterranea }\end{array}$ & MMB1 & ect $A B C / R /$ ask-ect & $\mathrm{o}$ & $\begin{array}{c}\text { betAB / } \\
\text { betIproXWV }\end{array}$ \\
\hline Ectothiorhodospiraceae & Nitrococcus mobilis & NB-231 & ectABC & $\begin{array}{l}\text { GMT- } \\
\text { DMT }\end{array}$ & betA/ \\
\hline Chromatiaceae & $\begin{array}{l}\text { Acidihalobacter } \\
\text { prosperus }\end{array}$ & DSM 14174 & ectABC & $\mathrm{o}$ & $\mathrm{o}$ \\
\hline
\end{tabular}

a Gene clusters are given and "/" denotes a separate locus of the genes in the genome. Color shades indicate different types of gene and gene associations, also marine (blue) and halophilic (rose) growth response of the bacteria. 


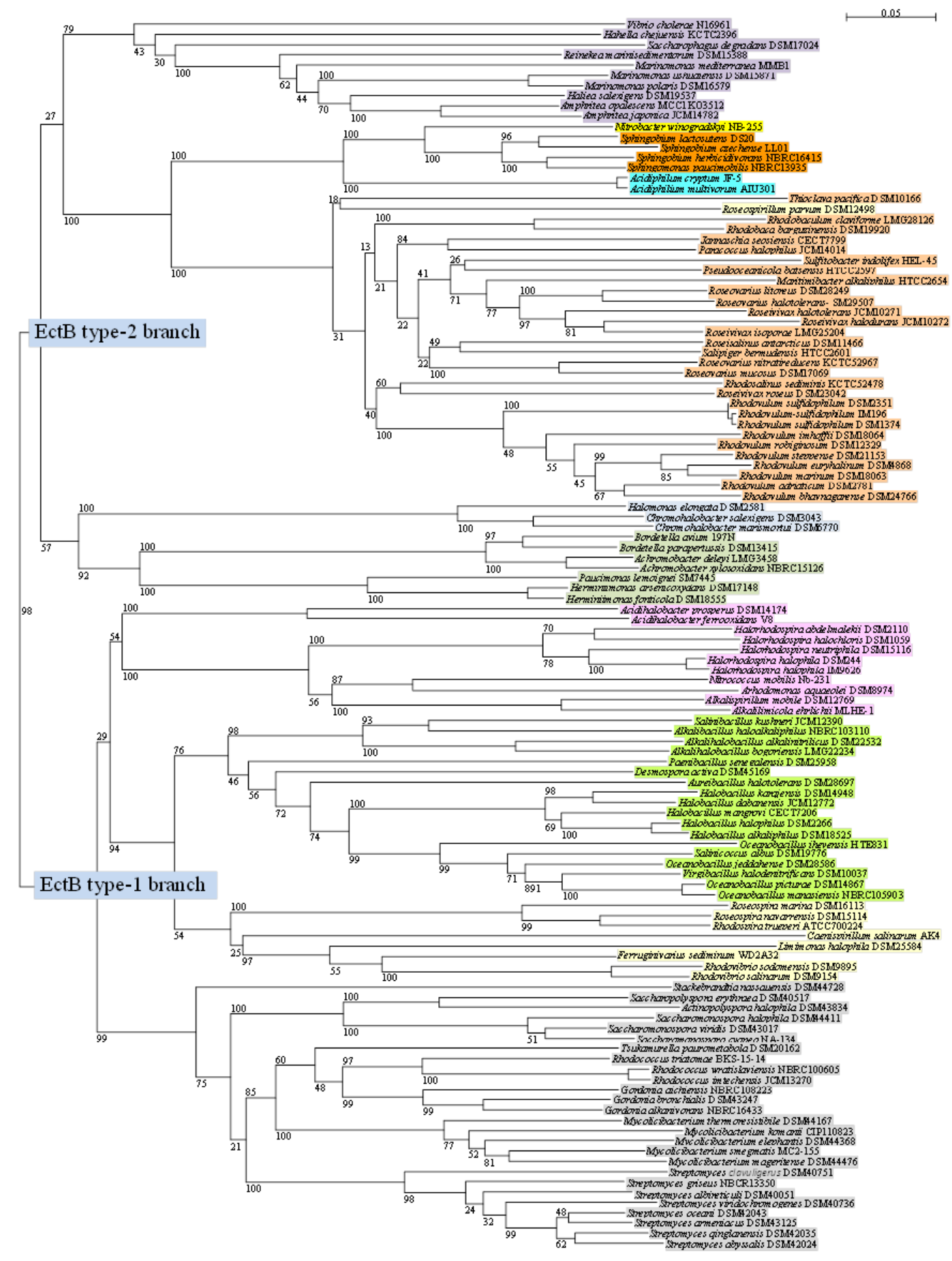

\begin{tabular}{|l|l|l|l|l|l|l|}
\hline \multicolumn{2}{|c|}{ Ectothiorhodospiraceae } & Halomonadaceae & other Gammaproteobacteria & Betaproteobacteria & Bacillales \\
\hline Rhodobacterales & Sphingomonadales & Acetobacteraceae & Rhodospirillaceae & Rhizobiales & Actinobacteria \\
\hline
\end{tabular}

Figure 2. The phylogeny of ectoine biosynthesis on the basis of sequences of diaminobutyrate-pyruvate aminotransferase EctB is shown in a neighbor-joining tree. Sequences and gene bank accession numbers are shown in the Supplementary Table S2. Bootstrap values expressed as percentages of 1000 replications are given at the branches. The bar indicates an evolutionary distance of 0.05 . The following color code highlights different systematic groups. 
Gammaproteobacteria are found in both branches-representatives of Ectothiorhodospiraceae in the EctB type-1 branch and representatives of Oceanospirillales, Cellvibrionales, and Vibrionales in the EctB type- 2 branch. According to genome analysis of the selected species and also BLAST search with representative EctB sequences, ectoine biosynthesis is absent from all tested Cyanobacteria, from Heliobacteria, Chlorobi, Chloroflexi, Chloracidobacterium, as well as from all studied phototrophic Betaproteobacteria, Rhizobiales, Chromatiaceae, and the Ectothiorhodospira species (Tables 1-3).

As shown in Figure 2, a first major phylogenetic branch (EctB type-1) contains four clearly separated groups: (1) the Ectothiorhodospiraceae, (2) Rhodospirillaceae including the non-phototrophic relatives, (3) Bacillales, and (4) Actinobacteria. This branch is characterized by a gene cluster lacking the regulatory ect $R$ gene and the ask_ect gene.

- The Ectothiorhodospiraceae form a branch with representatives of the genera Halorhodospira, Alkalilimnicola, Alkalispirillum, Nitrococcus, Arhodomonas, and Acidihalobacter, but lack species of Ectothiorhodospira, Thiorhodospira, and Ectothiorhodosinus, in which ectoine biosynthesis is absent. A cluster of the ect $A B C$ genes that lacks the regulatory gene is found in the extremely halophilic Halorhodospira species.

- The marine and halophilic Rhodospirillaceae also have an ectABC gene cluster and form deeply branching separate lineages with Rhodospira trueperi and the Roseospira species in one, Rhodovibrio sodomensis and Rhodovibrio salinarum and the non-phototrophic Ferruginivarius sediminum and Limimonas halophila in another, and Caenispirillum salinarum in a third lineage (Figure 2).

- Different lineages of the Bacillales branch are represented by species of the genera Halobacillus, of Oceanobacillus (including Salinicoccus albus (Staphylococcaceae) and Virgibacillus halodenitrificans), of Salinibacillus, Alkalibacillus and Alkalihalobacillus. Distinct separate lines of Aureibacillus halotolerans (Bacillaceae), Paenibacillus senegaliensis (Paenibacillaceae) and Desmospora activa (Thermoactinomycetaceae) are found (Figure 2).

- The branch of Actinobacteria shows distinct subbranches of Streptomyces, Mycolicibacterium, Gordonia, and Rhodococcus (associated with the Tsukamurella paurometabola) species, and of Saccharomonospora, Actinopolyspora, and Saccharopolyspora species (Figure 2). Distinct from these and as an outsider of the group is Stackebrandtia nassauensis. Common among many of the Actinobacteria is the ability to form hydroxyectoine, as demonstrated here by genome analysis of Mycolicibacterium thermoresistibile, and BLAST search with the EctD sequences from these bacteria (data not shown).

A second major phylogenetic branch (EctB type-2) is characterized by the presence of an extended gene cluster for ectoine biosynthesis, often including the regulatory gene $(e c t R)$ and a specific isoenzyme of aspartokinase (ask_ect). The EctB type-2 group shows considerable deeper branching points and is phylogenetically even more diverse compared to the EctB type-1 group (Figure 2).

The Alphaproteobacteria form two related subbranches. One of these is represented by Rhodobacterales, with numerous anaerobic and aerobic phototrophic bacteria, as well as chemotrophic relatives that are unable to perform photosynthesis and has an extended ask_ect_ectABCR gene cluster. Species of Rhodovulum and the related genera Roseivivax, Roseovarius, Rhodosalinus, and Roseisalinus are included (Table 2, Figure 2). However, in the related Rhodobacter species, ectoine biosynthesis and the ectABCR genes are absent. One distinct separate lineage is formed by Rhodobaca barguzinensis and Rhodobaculum claviforme. The marine Roseospirillum parvum is the only representative of Rhodospirillaceae within the type-2 group. Its gene cluster includes the regulatory gene (ect $A B C R)$ but lacks the ask_ect gene. However, this species and Thioclava pacifica (Rhodobacteraceae) are outsider of this subbranch.

A second subbranch of Alphaproteobacteria is distantly associated with the Rhodobacterales branch. It includes the aerobic phototrophic Acidiphilium multivorum (Acetobacteraceae, Rhodospirillales) and Acidiphilium cryptum (non-phototrophic), which also encode the formation of hydroxyectoine and have ectD included in the gene cluster ectRABCDask_ect (Table 2). The related phototrophic Acetobacteraceae Rhodopila globiformis and Paracrauro- 
coccus ruber are unable to produce ectoine (Table 2). A second lineage of this subbranch contains Nitrobacter winogradskyi (Rhizobiales) and representatives of the Sphingomonadales.

Although none of the phototrophic Betaproteobacteria included in this study was able to synthesize ectoine, in several chemotrophic Betaproteobacteria (Burkholderiales) EctB is present and a distinct branch of type-2 EctB sequences is formed. Two separate lineages include representatives of Alcaligenaceae (Achromobacter and Bordetella species) in one, and the Paucimonas (Burkholderiaceae) and Herminiimonas (Oxalobacteraceae) species in another lineage (Figure 2). An ectRABCD gene cluster was found in the genomes of Achromobacter xylosoxidans, Bordetella avium, Herminiimonas arsenicoxydans, and Paucimonas limoigeni (Table 4).

Two branches of Gammaproteobacteria are found among the EctB type-2 sequences. One is represented by Halomonadaceae with Halomonas elongata and Chromohalobacter salexigens and related species (ect $A B C /$ ectD), and associates distantly with the sequences of Betaproteobacteria. The second one is poorly associated and is quite distant to the branch of Alphaproteobacteria. It includes representatives of Oceanospirillaceae (Marinomonas and Amphritea species) and deeply branching lines with representatives of other families (Table 4, Figure 2). There is a considerable variation of the composition of the ect gene cluster in this branch (Marinomonas mediterranea: ect ABC/ectR/ask_ect; Hahella chejuvensis: ectABCD; Haliea salexigens: ectRABCask_ect), as shown in Table 4.

\subsection{Betaine Synthesis from Choline-Distribution of Bet Genes in Phototrophic Bacteria}

An alternative and independent pathway of betaine synthesis that starts from choline exists in a number of bacteria [49]. It depends on an external source of choline that needs to be taken up by the cells and is then converted into betaine. Thus, the availability of choline is a crucial factor that eliminates this pathway from consideration, as an important and independent option to adapt to high salt concentrations. Though this pathway offers a good chance for bacteria living in eutrophic locations rich in biomass and provide choline as the source, such habitats with extremes of salt concentrations are almost devoid of higher developed eukaryotes that could produce and release choline. Here, mass developments of halophilic microorganisms that would be the primary colonizers could be a possible source under such conditions. If the presence of this pathway is compared with the ability to cope with even low (marine) salt concentrations, it is then obvious that it does not play a primary role in conquering marine and hypersaline habitats. Most marine species that can perform the choline pathway, are not dependent on this pathway, but have alternative options of compatible solute biosynthesis. Examples are Rhodobaca barguzinensis (produces also ectoine), Rhodovibrio species (also have the ectoine and glycine-dependent pathway), Marichromatium gracile (also has the glycine-dependent pathway), and Ectothiorhodospira species (have the glycine-dependent pathway) (see Tables 2 and 3). The only marine species that exclusively rely on the choline-dependent pathway of biosynthesis for betaine synthesis (in addition to several transport systems) are members of the Rhizobiales including Fulvimarina pelagi, Hoeflea phototrophica, Rhodobium orientis, and the Afifella species (Table 2). It is also found in some freshwater bacteria, such as Rhodopseudomonas palustris, Rhodospirillum rubrum, and Rhodobacter species.

Quite interestingly, the choline-dependent pathway of betaine synthesis is also an additional option in a few extremely halotolerant species, which are capable of betaine synthesis from glycine and of ectoine synthesis. These include a few Rhodobacteraceae (species of Roseivivax, Rhodosalinus, and Roseovarius), as well as the Rhodovibrio species (Table 2).

\subsection{Transport System for Uptake of Glycine Betaine and Choline}

All marine and halophilic phototrophic bacteria have one or more transport systems for betaine or choline. This underlines the importance of transport to gain or regain osmolytes for successful adaptation to elevated salt concentrations. In contrast, freshwater phototrophic bacteria not only lack possibilities of biosynthesis but also of common 
transport systems for betaine, ectoine, and related osmolytes. While there are no obvious correlations between these transport systems and the biosynthetic pathways present, various phylogenetic groups have characteristic sets of transport systems for betaine, choline, and possibly ectoine and related osmolytes.

The most common and highly variable system is the ABC transporter ProU, which is present in different distinct variants and in different association with other genes. Often multiple forms are found in one and the same bacterium (Figure 3, Tables 1-3).

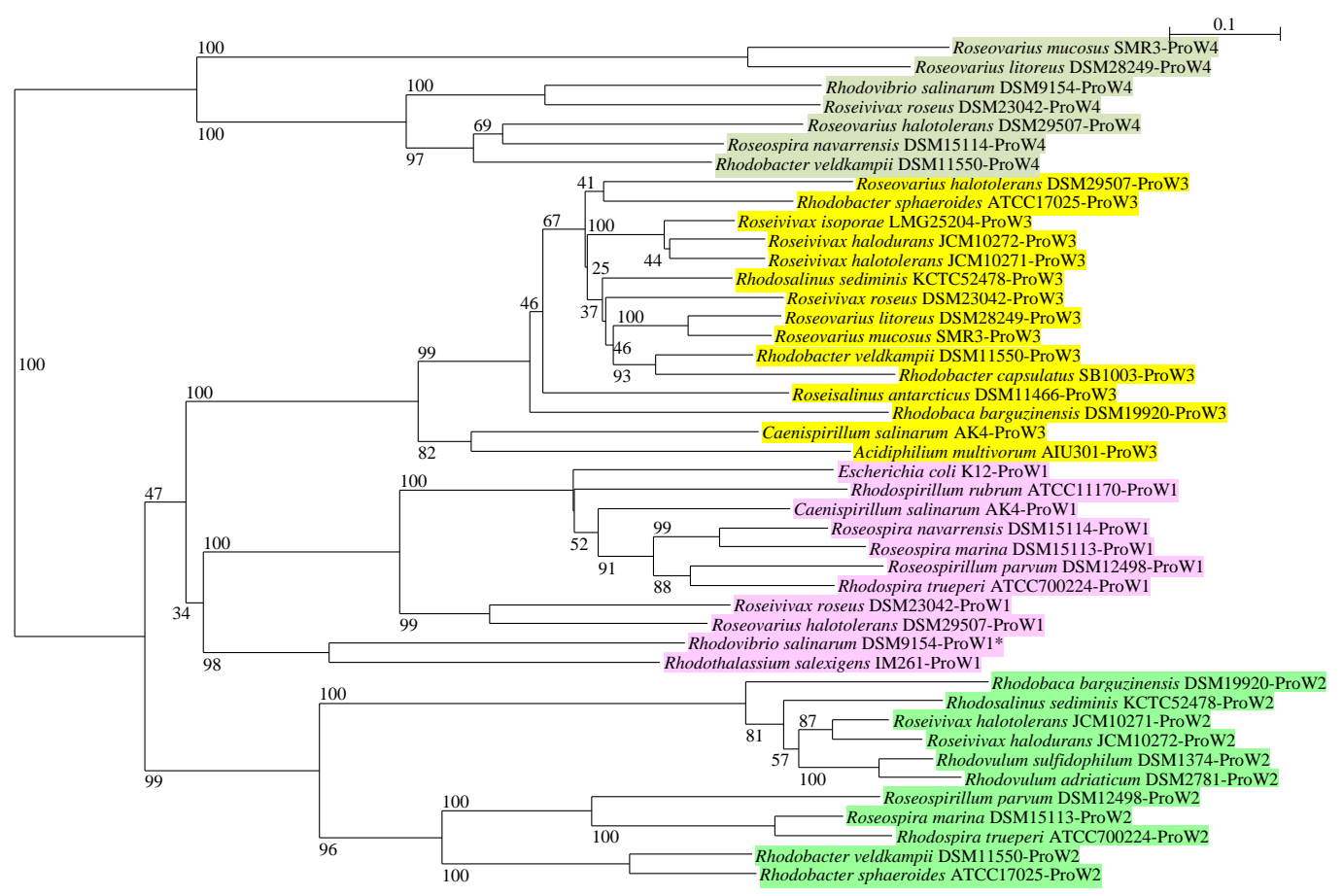

\section{\begin{tabular}{l|l|l|l} 
ProW1 & ProW2 & ProW3 & ProW4
\end{tabular}}

Figure 3. The phylogeny of the permease protein ProW of the L-proline/glycine betaine transport system ProU is shown in a neighbor-joining tree. The ProW1-ProW4 gene clusters are defined with Table 1. Sequences and gene bank accession numbers are shown in Supplementary Table S3. Bootstrap values expressed as percentages of 1000 replications are given at the branches. The bar indicates an evolutionary distance of 0.1 . The following color code is used for the different ProW sequence types.

According to the ProW sequences, at least four distinct types of this transporter can be distinguished (Figure 3). One separate proVWX gene cluster is related to the E. coli proU cluster (type ProW1). Another separate proXWV cluster represents a second phylogenetic group (type ProW2). Phylogenetically distinct is a third group (type ProW3), which has proXWV genes associated with a cluster of genes for choline-dependent betaine biosynthesis (betABI-proXWV), e.g., in Rhodosalinus sediminis. A fourth group with a particularly large ProW sequences (type ProW4) is clearly distant to the first three groups. Finally, a gene cluster including a YehZ betaine binding protein is especially found in some species restricted to freshwater habitats (data not shown). In fact, YehZYXW mediated activity in $E$. coli was inhibited at increased salinity and it was concluded that this transport system is not relevant to osmotic protection [50]. A branch of sequences of ProW of this type of transport system is distantly related to the four others and includes sequences of the E. coli YehW (data not shown). This was not considered in the phylogenetic tree of ProW sequences (Figure 3). In this tree of selected ProW sequences, the presence of several sequence types 
is demonstrated in Rhodobacter veldkampii (types W2, W3, W4), Rhodobaca barguzinensis (types W2, W3), Roseovarius halotolerans (types W1, W3, W4), and others. Though sequence variations might suggest possible differences in catalytic properties, gene regulation or substrate specificities between the 4 types of ProU transport systems, these are yet to be demonstrated in future studies.

Common to most marine and halophilic phototrophic bacteria, no matter whether they synthesize betaine or ectoine, is the BetT secondary transporter, which is known as a specific choline transport system in E. coli, but is shown to specifically transport betaine in Aphanothece halophytica [18].

Another secondary transporter for glycine betaine, OpuD, is found in the freshwater Betaproteobacteria Rhodoferax fermentans and Rubrivivax gelatinosus, as only a transport system for betaine.Whereas, it is present in the marine Caenispirillum salinarum as well as in the extreme halophilic Halorhodospira species, both of which synthesize betaine and ectoine, (not in Hlr. neutriphila) together with BetT and ProU (type W1) (not in Hlr. halochloris). The only species of Ectothiorhodospira that encodes OpuD is Ectothiorhodospira haloalkaliphila.

The ABC transporter OpuA was found together with BetT in a small group of marine Chromatiaceae producing betaine (Thiocapsa, Thiocystis, Marichromatium, Imhoffiella, and Thiorhodococcus species), and also in all Ectothiorhodospira species. In all of these latter species, bet $T$ clusters with the opuA genes (betT-opuAA,AB,AC) and in a few Chromatiaceae, a copy of bet $T$ also specifically associates with the opuAC gene (Table 3 ). In a few cases, a chimera of the proU and opuA genes occur. In marine Prosthecochloris vibrioformis, this is proVopuAB,AC, in Rhodovibrio salinarum and also in two Chromatiaceae (Rhabdochromatium marinum and Thiorhodovibrio winogradskyi) this is proVWopuAC. Furthermore, a chimera between opuC and proU (opuCB-proXV) is annotated in the Roseiflexus species.

\subsection{Evolutionary Considerations}

From an evolutionary point of view, the primary adaptation to high solute concentrations clearly requires a biosynthesis of compatible solutes. Already in the early prokaryote era the ability for biosynthesis and accumulation of organic solutes was a prerequisite for archaic eubacteria to conquer saline and hypersaline environments. Inorganic ions and common simple organic metabolites might have allowed a basic osmotic adaptation in freshwater and marine bacteria. Potassium very likely is a suitable candidate and is responsible for a kind of basic osmotic adaptation in many bacteria in which it accumulates together with glutamic acid, and thereby contributes to the overall osmotic balance [7]. In the extremely halophilic Archaea, the Halobacteria, it is even the primary osmolyte and accumulates to several molar concentrations [51,52]. In freshwater bacteria such as E. coli, its uptake or release makes possible rapid responses to small changes in osmotic conditions. For osmotic adaptation of marine and halophilic eubacteria, however, it is not important.

In marine eubacteria, a number of non-charged neutral organic molecules contribute to different degrees in achieving osmotic balance. As was shown for Cyanobacteria, the degree of salt tolerance depends on the kind of osmolytes that are accumulated. Only limited osmotic adaptation to lower ranges of salt concentrations is possible by carbon compounds such as sugars (sucrose, trehalose), glucosylglycerol, and others [1,6,7,11-13]. The advantage of accumulating these compounds is the comparable cheap biosynthesis and the absence of nitrogen as one of the most severe limiting elements in the environment. The disadvantage is their comparatively low compatibility or solubility. For example, trehalose has a solubility of approximately $2 \mathrm{M}$, ectoine of $3.87 \mathrm{M}$, and glycine betaine of 13.6 M. The extreme compatibility of betaine, which goes hand in hand with its excellent solubility, and the almost perfect ability to protect macromolecules against denaturation even at very high concentrations, make betaine the top compatible solute. The excellent osmotic protection of betaine is also reflected in the finding, that the phototrophic bacteria that have most successfully adapted to extremely high salt concentrations accumulate betaine as compatible solute through de novo biosynthesis from glycine. In fact, a striking dependence on betaine synthesis for adaption, to live in extreme and even moderate salt 
concentrations as found in this study, points out that the kind of osmolytes accumulated in a critical way determine the success of salt adaptation. Therefore, the establishment of betaine biosynthesis is expected to represent an evolutionary breakthrough in osmotic adaptation of eubacteria to high salt concentrations, and is considered to be a prerequisite to conquer highly saline environments.

Nonetheless, the synthesis and accumulation of high concentrations of betaine is a costly process. Though glycine, the immediate biosynthetic precursor of betaine, is a common intermediate of central metabolic processes and can be transformed to betaine with a few enzymatic steps, the three methylation steps have a high energy demand. Additionally, the accumulation of several molar concentrations can be easily limited by the availability of nitrogen. Therefore, bacteria that have no shortage in energy and nitrogen supply, such as phototrophic bacteria, which use sunlight as an energy source and are capable of fixing dinitrogen, are likely to be the first and also to be the most successful in conquering highly saline habitats. In fact, mass developments of phototrophic bacteria regularly occur in salt and soda lakes, as well as in coastal lagoons, and cause colored blooms [1,7,53-55].

Compared to betaine, the accumulation of ectoine has two major and significant disadvantages. The physiological disadvantage of ectoine is its low solubility compared to betaine, which limits its accumulation and protective action at hypersaline salt concentrations. Its ecological disadvantage is the content of 2 nitrogen atoms in the molecule, which doubles the requirement for nitrogen compared to betaine. This restricts accumulation to environments with a high content of combined nitrogen compounds, unless nitrogen can be supplied by nitrogen fixation. In this case, the energy requirement for osmotic adaptation is further increased, because twice as much nitrogen has to be fixed, compared to betaine synthesis. Phylogenetically, it appears as a late event compared to betaine biosynthesis. The most deeply branching points within both type- 1 and type- 2 EctB sequences are those of the Gammaproteobacteria, forming one branch in the type-1 group and two branches in the type-2 group. Quite remarkably, also the structure of the ect gene cluster is much more variable in Gammaproteobacteria compared to other groups. In addition to the ect $A B C$ genes, either ectD or ask_ect or ect $R$, or combinations thereof might be present, but might not be part of the gene cluster (Table 3). Therefore, it is assumed that the two types of EctB sequences have their origin in ancestors of the Gammaproteobacteria, which might also represent the most ancient ectoine producers. Both phylogenetic lineages might have separated early and given rise to the two independent major branches. Today, the two most prominent and best studied representatives of the two branches that have evolved are found in the Gammaproteobacteria: Halorhodospira halochloris (type-1) and Halomonas elongata (type-2). Among phototrophic bacteria, ectoine biosynthesis is restricted to a few distinct groups, with representatives of Gammaproteobacteria (Halorhodospira species) and Alphaproteobacteria (Rhodobacterales and Rhodospirillales).

\section{Conclusions}

The comprehensive analysis of more than 130 genomes of phototrophic bacteria gives insight into their ability to synthesize the compatible solutes betaine and ectoine, and to take up these compounds. The potential to accumulate these compatible solutes and the kind of solute accumulated, clearly define the range of salt concentrations and the habitats where these bacteria can develop. The data suggest that betaine is the primary compatible solute at high salt concentrations and the most ancient one in evolutionary terms. All halophilic phototrophic bacteria rely on betaine synthesis, and only few of them have additional options of ectoine biosynthesis, or betaine synthesis from choline. Ectoine synthesis as a sole compatible solute is only found in some marine bacteria, in particular Rhodobacteraceae and the acidiphilic Acidiphilum species. This is in accord with its potential to achieve osmotic protection in moderately halotolerant marine bacteria. As information on the presence of choline in marine and hypersaline habitats is missing, it is unclear whether the transformation of choline to betaine is of relevance for osmotic adaptation in 
these environments. Only few marine species of the Rhizobiales, exclusively rely on this pathway, but in addition have several transport systems (betT, ProU) to take up betaine and ectoine from the environment. Therefore, these bacteria are more limited than others to adapt to marine salt concentrations, and their occurrence is restricted to habitats where appropriate solutes are available.

The possibility to take up and accumulate compatible solutes or their precursors from the environment and also from the culture media, was been largely neglected in previous studies on salt relations of marine and halophilic species. In order to consider osmotic adaptation in an ecological context and to characterize salt relations of individual species, the potential of uptake needs to be considered. In complex microbial communities such a microbial mats, the study of synthesis, release and uptake at the community level would be rewarding and would shed light on possible complex syntrophic interactions based on the exchange of compatible solutes between members of the community. In view of the variety and the presence of multiple transport systems in several species, characterization of their catalytic properties and regulation is necessary to identify their functional roles. Quite rewarding from both an evolutionary point of view and from a functional context, should be the analysis of chimeric transport systems as they occur in Prosthecochloris vibrioformis (proVopuAB,AC) and in the Roseiflexus species (opuCBproXV).

Despite the fact that synthesis and accumulation of betaine is common to all known halophilic phototrophic bacteria, there is a considerable variation in gene arrangement and formation of gene clusters. In addition, fused GMT-DMT genes occur in some groups of the studied bacteria and a second type called the B-type of GMT sequences is found in several species. The phylogeny of the biosynthesis pathway (of GMT), suggests that the roots are manifested early in bacterial evolution and are most likely before diversification of bacteria as we know today. The recognition of two major phylogenetic branches of Cyanobacteria and their relations to others suggests that they represent one of the most ancient betaineproducing bacterial phyla and betaine biosynthesis and might have originated in one of their early ancestor. In another very ancient phylum of phototrophic bacteria, the Chlorobi (green sulfur bacteria), betaine biosynthesis was found only in Chloroherpeton thalassium. This is one of the most ancient representatives of green sulfur bacteria that is known and the deeply rooted branch of its GMT sequence points out that it might represent one of the most ancient betaine producers as well. Other green sulfur bacteria such as the Chlorobium and Chlorobaculum species and their relatives might have lost the capability of betaine synthesis during adaptation to freshwater habitats. Most remarkable is the occurrence of B-type GMT sequences, which are phylogenetically distant to all other GMT sequences, and might represent a much older system of betaine biosynthesis. Such a GMT gene is included in a gene cluster for betaine biosynthesis only in the Rhodovibrio species. Therefore, studies of betaine biosynthesis of the Rhodovibrio species should be quite rewarding.

In addition to these few examples, data are presented form a comprehensive basis for more detailed studies on osmotic adaptation of phototrophic bacteria.

Supplementary Materials: The Supplementary Material for this article is available online at https: //www.mdpi.com/2076-2607/9/1/46/s1.

Author Contributions: Cultivation of bacterial cultures, DNA extraction and purification were performed by T.R.; genomic sequencing and quality assurance by S.K. and A.K.; sequence assembly by S.C.N.; sequence annotation, retrieval of sequences from annotated genomes and databases, phylogenetic calculations and design of the study, as well as writing of the manuscript was done by J.F.I. All authors contributed to and approved the work for publication. All authors have read and agreed to the published version of the manuscript.

Funding: This research received no external funding.

Institutional Review Board Statement: Not applicable.

Informed Consent Statement: Not applicable. 
Data Availability Statement: Data on gene and genome sequences and accession numbers are contained within supplementary material of the article. All sequence data are available in a publicly accessible repository of gene bank.

Conflicts of Interest: The authors declare no conflict of interest.

\section{References}

1. Imhoff, J.F. Minireview-True marine and halophilic anoxygenic phototrophic bacteria. Arch. Microbiol. 2001, 176, 243-254. [CrossRef] [PubMed]

2. Imhoff, J.F. Diversity of anaerobic anoxygenic phototrophic purple bacteria. In Modern Topics in the Phototrophic Prokaryotes: Environmental and Applied Aspects; Hallenbeck, P.C., Ed.; Springer: Cham, Switzerland, 2017; pp. 47-85.

3. Brown, A.D. Microbial water stress. Bacteriol. Rev. 1976, 40, 803-846. [CrossRef] [PubMed]

4. Galinski, E.A.; Trüper, H.G. Betaine, a compatible solute in the extremely halophilic phototrophic bacterium Ectothiorhodospira halochloris. FEMS Microbiol. Lett. 1982, 13, 357-360. [CrossRef]

5. Imhoff, J.F.; Rodriguez-Valera, F. Betaine is the main compatible solute of halophilic eubacteria. J. Bacteriol. 1984, 160, 478-479. [CrossRef]

6. Imhoff, J.F. Osmoregulation and compatible solutes in eubacteria. FEMS Microbiol. Rev. 1986, 39, 57-66. [CrossRef]

7. Imhoff, J.F. Osmotic adaptation in halophilic and halotolerant microorganisms. In The Biology of Halophilic Bacteria; Vreeland, R.W., Hochstein, L.J., Eds.; The CRC Press: Boca Raton, FL, USA, 1993; pp. 211-253.

8. Trüper, H.G.; Galinski, E.A. Biosynthesis and fate of compatible solutes in extremely halophilic phototrophic eubacteria. FEMS Microbiol. Rev. 1990, 75, 247-254. [CrossRef]

9. Galinski, E.A.; Pfeiffer, H.-P.; Trüper, H.G. 1,4,5,6-Tetra-hydro-2-methyl-4-pyrimidinecarboxylic acid: A novel cyclic amino acid from halophilic phototrophic bacteria of the genus Ectothiorhodospira. Eur. J. Biochem. 1985, 149, 135-139. [CrossRef]

10. Czech, L.; Hermann, L.; Stöveken, N.; Richter, A.A.; Höeppner, A.; Smits, S.H.J.; Heider, J.; Bremer, E. Role of the Extremolytes Ectoine and Hydroxyectoine as Stress Protectants and Nutrients: Genetics, Phylogenomics, Biochemistry, and Structural Analysis. Genes 2018, 9, 177. [CrossRef]

11. Mackay, M.A.; Norton, R.S.; Borowitzka, L.J. Organic Osmoregulatory Solutes in Cyanobacteria. J. Gen. Microbiol. 1984, 130, 2177-2191. [CrossRef]

12. Severin, J.; Wohlfarth, A.; Galinski, E.A. The predominant role of recently discovered tetrahydropyrimidines for the osmoadaptation of halophilic eubacteria. J. Gen. Microbiol. 1992, 138, 1629-1638. [CrossRef]

13. Welsh, D.T.; Herbert, R.A. Identification of organic solutes accumulated by purple and green sulfur bacteria during osmotic stress using natural abundance 13C nuclear magnetic resonance spectroscopy. FEMS Micobiol. Ecol. 1993, 13, 145-150. [CrossRef]

14. Nyyssölä, A.; Kerovuo, J.; Kaukinen, P.; Von Weymarn, N.; Reinikainen, T. Extreme Halophiles Synthesize Betaine from Glycine by Methylation. J. Biol. Chem. 2000, 275, 22196-22201. [CrossRef] [PubMed]

15. Nyyssölä, A.; Reinikainen, T.; Leisola, M. Characterization of Glycine Sarcosine N-Methyltransferase and Sarcosine Dimethylglycine N-Methyltransferase. Appl. Environ. Microbiol. 2001, 67, 2044-2050. [CrossRef] [PubMed]

16. Waditee, R.; Tanaka, Y.; Aoki, K.; Hibino, T.; Jikuya, H.; Takano, J.; Takabe, T.; Takabe, T. Isolation and functional characterization of $N$-methyltransferases that catalyze betaine synthesis from glycine in a halotolerant photosynthetic organism Aphanothece halophytica. J. Biol. Chem. 2003, 278, 4932-4942. [CrossRef]

17. Andresen, P.A.; Kaasen, I.; Styrvold, O.B.; Boulnois, G.; Strøm, A.R. Molecular cloning, physical mapping and expression of the bet genes governing the osmoregulatory choline-glycine betaine pathway of Escherichia coli. J. Gen. Microbiol. 1988, 134, 1737-1746. [CrossRef]

18. Laloknam, S.; Tanaka, K.; Buaboocha, T.; Waditee, R.; Incharoensakdi, A.; Hibino, Y.; Tanaka, Y.; Takabe, T. Halotolerant cyanobacterium Aphanothece halophytica contains a betaine transporter active at alkaline $\mathrm{pH}$ and high salinity. Appl. Environ. Microbiol. 2006, 72, 6018-6026. [CrossRef]

19. Peters, P.; Galinski, E.A.; Trüper, H.G. The biosynthesis of ectoine. FEMS Microbiol. Lett. 1990, 71, 157-162. [CrossRef]

20. Ono, H.; Sawada, K.; Khunajakr, N.; Tao, T.; Yamamoto, M.; Hiramoto, M.; Shinmyo, A.; Takano, M.; Murooka, Y. Characterization of biosynthetic enzymes for ectoine as a compatible solute in a moderately halophilic eubacterium Halomonas elongata. J. Bacteriol. 1999, 181, 91-99. [CrossRef]

21. Louis, P.; Galinski, E.A. Characterization of genes for the biosynthesis of the compatible solute ectoine from Marinococcus halophilus and osmoregulated expression in Escherichia coli. Microbiology 1997, 143, 1141-1149. [CrossRef]

22. Inbar, L.; Labidot, A. The structure and biosynthesis of new tetrahydropyrimidine derivatives in actinomycin D producer Streptomyces parvulus. Use of 13C- and 15N-labeled L-glutamate and 13C and 15N NMR spectroscopy. J. Biol. Chem. 1988, 263, 16014-16022.

23. Widderich, N.; Höppner, A.; Pittelkow, M.; Heider, J.; Smits, S.H.; Bremer, E. Biochemical properties of ectoine hydroxylase from extremophiles and their wide taxonomic distribution among microorganisms. PLoS ONE 2014, 9, e93809. [CrossRef] [PubMed]

24. Stöveken, N.; Pittelkow, M.; Sinner, T.; Jensen, R.A.; Heider, J.; Bremer, E. A specialized aspartokinase enhances the biosynthesis of the osmoprotectants ectoine and hydroxyectoine in Pseudomonas stutzeri A1501. J. Bacteriol. 2011, 193, 4456-4468. [CrossRef] [PubMed] 
25. Reshetnikov, A.S.; Khmelenina, V.N.; Trotsenko, Y.A. Characterization of the ectoine biosynthesis genes of haloalkalotolerant obligate methanotroph "Methylomicrobium alcaliphilum 20Z". Arch. Microbiol. 2006, 184, 286-297. [CrossRef] [PubMed]

26. Sleator, R.D.; Hill, C. Bacterial osmoadaptation: The role of osmolytes in bacterial stress and virulence. FEMS Microbiol. Rev. 2002, 26, 49-71. [CrossRef]

27. Kempf, B.; Bremer, E. Uptake and synthesis of compatible solutes as microbial stress response to high-osmolality environments Arch. Microbiol. 1998, 170, 319-330. [CrossRef]

28. Pfennig, N.; Trüper, H.G. Isolation of members of the families Chromatiaceae and Chlorobiaceae. In The Prokaryotes, a Handbook on Habitats, Isolation and Identification of Bacteria; Starr, M.P., Stolp, H., Trüper, H.G., Balows, A., Schlegel, H.G., Eds.; Springer: New York, NY, USA, 1981; pp. 279-289.

29. Imhoff, J.F. The Chromatiaceae. In The Prokaryotes. A Handbook on the Biology of Bacteria, 3rd ed.; Dworkin, M., Falkow, S., Rosenberg, E., Schleifer, K.-H., Stackebrandt, E., Eds.; Springer: New York, NY, USA, 2006; Volume 6, pp. 846-873.

30. Imhoff, J.F. Anoxygenic phototrophic bacteria. In Methods in Aquatic Bacteriology; Austin, B., Ed.; John Wiley \& Sons: Chichester, UK, 1988; pp. 207-240.

31. Imhoff, J.F.; Rahn, T.; Künzel, S.; Neulinger, S.C. New insights into the metabolic potential of the phototrophic purple bacterium Rhodopila globiformis DSM $161^{\mathrm{T}}$ from its draft genome sequence and evidence for a vanadium-dependent nitrogenase. Arch. Microbiol. 2018, 200, 847-857. [CrossRef]

32. Bolger, A.M.; Lohse, M.; Usadel, B. Trimmomatic: A flexible trimmer for Illumina sequence data. Bioinformatics 2014, 30, 2114-2120. [CrossRef]

33. Morgulis, A.; Gertz, E.M.; Schäffer, A.A.; Agarwala, R. A Fast and Symmetric DUST Implementation to Mask Low-Complexity DNA Sequences. J. Comput. Biol. 2006, 13, 1028-1040. [CrossRef]

34. Nurk, S.; Bankevich, A.; Antipov, D.; Gurevich, A.; Korobeynikov, A.; Lapidus, A. Assembling genomes and mini-metagenomes from highly chimeric reads. In Research in Computational Molecular Biology; Deng, M., Jiang, R., Sun, F., Zhang, X., Eds.; Springer: Heidelberg, Germany, 2013; pp. 158-170.

35. Bankevich, A.; Nurk, S.; Antipov, D.; Gurevich, A.A.; Dvorkin, M.; Kulikov, A.S.; Lesin, V.M.; Nikolenko, S.I.; Pham, S.; Prjibelski, A.D.; et al. SPAdes: A new genome assembly algorithm and its applications to single-cell sequencing. J. Comput. Biol. 2012, 19, 455-477. [CrossRef]

36. Boetzer, M.; Henkel, C.V.; Jansen, H.J.; Butler, D.; Pirovano, W. Scaffolding pre-assembled contigs using SSPACE. Bioinformatics 2011, 27, 578-579. [CrossRef]

37. Aziz, R.K.; Bartels, D.; Best, A.A.; DeJongh, M.; Disz, T.; Edwards, R.A.; Formsma, K.; Gerdes, S.; Glass, E.M.; Kubal, M.; et al. The RAST Server: Rapid Annotations using Subsystems Technology. BMC Genom. 2008, 9, 75. [CrossRef] [PubMed]

38. Altschul, S.F.; Madden, T.L.; Schäffer, A.A.; Zhang, J.; Zhang, Z.; Miller, W.; Lipman, D. Gapped BLAST and PSI-BLAST: A new generation of protein database search programs. Nucleic Acids Res. 1997, 25, 3389-3402. [CrossRef] [PubMed]

39. Overbeek, R.; Olson, R.; Pusch, G.D.; Olsen, G.J.; Davis, J.J.; Disz, T.; Edwards, R.A.; Gerdes, S.; Parrello, B.; Shukla, M.; et al. The SEED and the Rapid Annotation of microbial genomes using Subsystems Technology (RAST). Nucleic Acids Res. 2014, 42, D206-D214. [CrossRef] [PubMed]

40. Larkin, M.A.; Blackshields, G.; Brown, N.P.; Chenna, R.; Mcgettigan, P.A.; McWilliam, H.; Valentin, F.; Wallace, I.M.; Wilm, A.; Lopez, R.; et al. Clustal W and Clustal X version 2.0. Bioinformatics 2007, 23, 2947-2948. [CrossRef]

41. Saitou, N.; Nei, M. The neighbor-joining method: A new method for reconstructing phylogenetic trees. Mol. Biol. Evol. 1987, 4, 406-425. [CrossRef]

42. Perrière, G.; Gouy, M. WWW-query: An on-line retrieval system for biological sequence banks. Biochimie 1996, 78, 364-369. [CrossRef]

43. Reed, R.; Stewart, W.D.P. Osmotic adjustment and organic solute accumulation in unicellular cyanobacteria from freshwater and marine habitats. Mar. Biol. 1985, 88, 1-9. [CrossRef]

44. Reed, R.; Borowitzka, L.J.; Mackay, M.A.; Chudek, J.A.; Foster, R.; Warr, S.C.; Moort, D.J.; Stewart, W.D.P. Organic solute accumulation in osmotically stressed cyanobacteria. FEMS Microbiol. Rev. 1986, 39, 51-56. [CrossRef]

45. Klähn, S.; Hagemann, M. Compatible solute biosynthesis in cyanobacteria. Environ. Microbiol. 2011, 13, 551-562. [CrossRef]

46. Imhoff, J.F.; Rahn, T.; Künzel, S.; Neulinger, S.C. Phylogeny of anoxygenic photosynthesis based on protein sequences of the photosynthetic reaction center and of bacteriochlorophyll biosynthesis. Microorganisms 2019, 7, 576. [CrossRef]

47. Imhoff, J.F.; Petri, R.; Süling, J. Reclassification of species of the spiral-shaped phototrophic purple nonsulfur bacteria of the alpha-proteobacteria: Description of the new genera Phaeospirillum gen. nov., Rhodovibrio gen. nov., Rhodothalassium gen. nov. and Roseospira gen. nov. as well as transfer of Rhodospirillum fulvum to Phaeospirillum fulvum comb. nov., of Rhodospirillum molischianum to Phaeospirillum molischianum comb. nov., of Rhodospirillum salinarum to Rhodovibrio salinarum comb. nov., of Rhodospirillum sodomense to Rhodovibrio sodomensis comb. nov., of Rhodospirillum salexigens to Rhodothalassium salexigens comb. nov., and of Rhodospirillum mediosalinum to Roseospira mediosalina comb. nov. Int. J. Syst. Bacteriol. 1998, 48, 793-798. [PubMed]

48. Ramana, V.V.; Chakravarthy, S.K.; Ramaprasad, E.V.V.; Thiel, V.; Imhoff, J.F.; Sasikala, C.; Ramana, C.V. Emended description of the genus Rhodothalassium Imhoff et al., 1998 and proposal of Rhodothalassiaceae fam. nov. and Rhodothalassiales ord. nov. Syst. Appl. Microbiol. 2013, 36, 28-32. [CrossRef] [PubMed]

49. Cánovas, D.; Vargas, C.; Csonka, L.N.; Ventosa, A.; Nieto, J.J. Synthesis of Glycine Betaine from Exogenous Choline in the Moderately Halophilic Bacterium Halomonas elongata. Appl. Environ. Microbiol. 1998, 64, 4095-4097. [CrossRef] [PubMed] 
50. Lang, S.; Cressatti, M.; Mendoza, K.E.; Coumoundouros, C.N.; Plater, S.M.; Culham, D.E.; Kimber, M.S.; Wood, J.M. YehZYXW of Escherichia coli is a low-affinity, non-osmoregulatory betaine-specific ABC transporter. Biochemistry 2015, 54, 5735-5747. [CrossRef] [PubMed]

51. Christian, J.H.G.; Whalto, J.A. Solute concentrations within cells of halophilic and non-halophilic bacteria. Biochim. Biophys. Acta 1962, 65, 506-508. [CrossRef]

52. Kushner, D.J. (Ed.) Life in high salt and solute concentrations: Halophilic bacteria. In Microbial Life in Extreme Environments; Academic Press: New York, NY, USA; London, UK, 1978; pp. 317-368.

53. Imhoff, J.F.; Hashwa, F.; Trüper, H.G. Isolation of extremely halophilic phototrophic bacteria from the alkaline Wadi Natrun, Egypt. Arch. Hydrobiol. 1978, 84, 381-388.

54. Imhoff, J.F.; Sahl, H.G.; Soliman, G.S.H.; Trüper, H.G. The Wadi Natrun: Chemical composition and microbial mass developments in alkaline brines of Eutrophic Desert Lakes. Geomicrobiol. J. 1979, 1, 219-234. [CrossRef]

55. Imhoff, J.F. Anoxygenic phototrophic bacteria from extreme environments. In Modern Topics in the Phototrophic Prokaryotes: Environmental and Applied Aspects; Hallenbeck, P.C., Ed.; Springer: Cham, Switzerland, 2017; pp. 427-480. 